This item was submitted to Loughborough's Research Repository by the author.

Items in Figshare are protected by copyright, with all rights reserved, unless otherwise indicated.

\title{
Application of filtration blocking models to describe fouling and transmission of large plasmids DNA in sterile filtration
}

PLEASE CITE THE PUBLISHED VERSION

http://dx.doi.org/10.1016/j.memsci.2013.02.055

PUBLISHER

(C) Elsevier

VERSION

AM (Accepted Manuscript)

LICENCE

CC BY-NC-ND 4.0

\section{REPOSITORY RECORD}

Affandy, Affaro, Eli Keshavarz-Moore, and Hendrik K. Versteeg. 2019. "Application of Filtration Blocking Models to Describe Fouling and Transmission of Large Plasmids DNA in Sterile Filtration”. figshare. https://hdl.handle.net/2134/13364. 
This item was submitted to Loughborough's Institutional Repository (https://dspace.lboro.ac.uk/) by the author and is made available under the following Creative Commons Licence conditions.

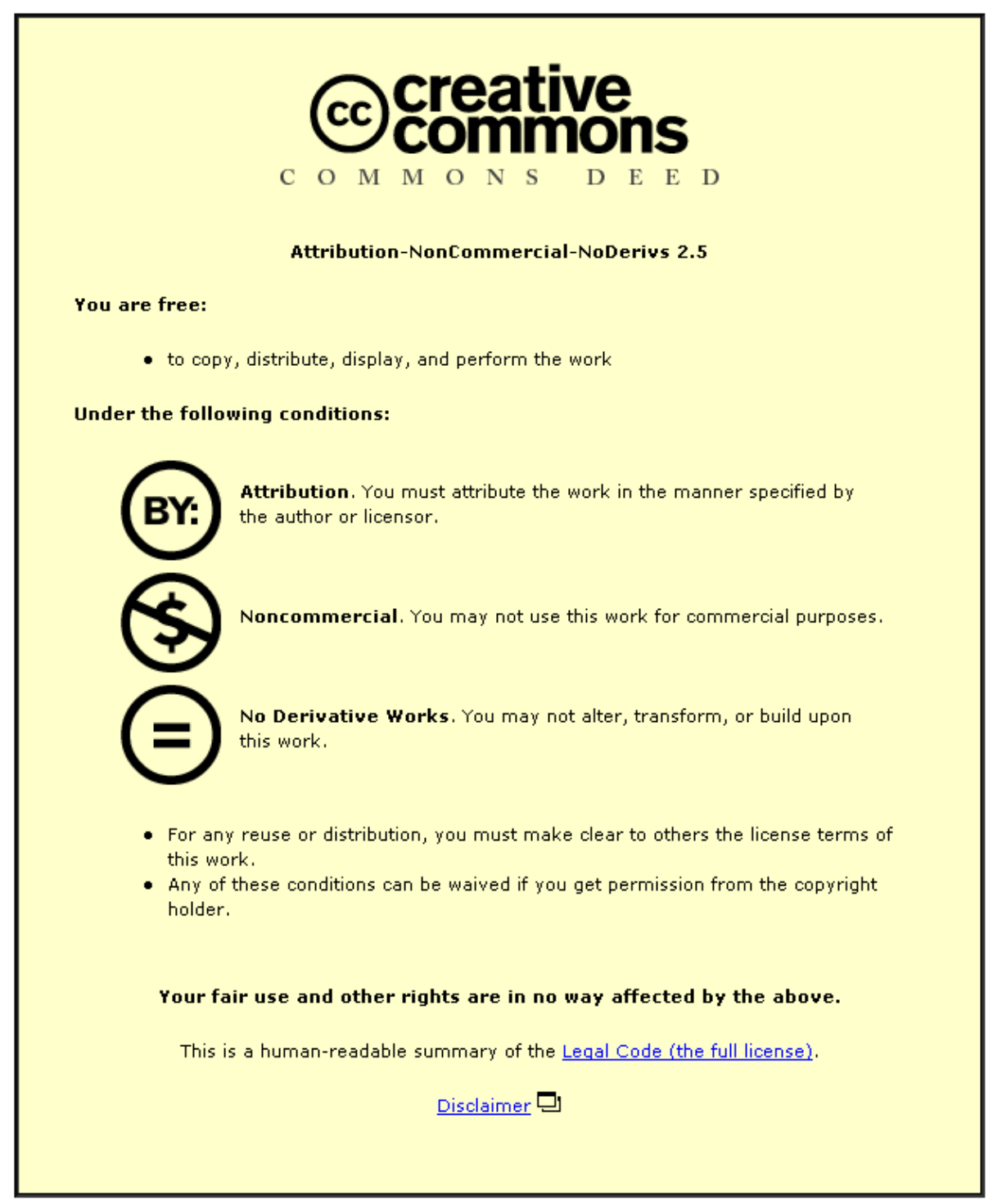

For the full text of this licence, please go to: http://creativecommons.org/licenses/by-nc-nd/2.5/ 
Elsevier Editorial System(tm) for Membrane Science

Manuscript Draft

Manuscript Number: JMS-121468R1

Title: Application of filtration blocking models to describe fouling and transmission of large plasmids DNA in sterile filtration

Article Type: Full Length Article

Keywords: Sterile filtration, plasmid DNA, fouling, blocking models, filtration law

Corresponding Author: Mr. Henk Versteeg,

Corresponding Author's Institution: Loughborough University

First Author: Affaro Affandy, PhD Biochemical Engineering

Order of Authors: Affaro Affandy, PhD Biochemical Engineering; Eli Keshavarz-Moore, PhD

Biochemical Engineering; Henk K Versteeg, MEng Mechanical Engineering

Abstract: Sterile filtration is considered as a final step in processing pharmaceutical grade plasmid DNA. During the development of the filtration process, fundamental understanding on the mechanism of fouling is critical to improve filtration operations. The mechanism of fouling of pQR150 (20 kb) and pGEc47 (56 kb) plasmids DNA during constant pressure filtration inside $0.22 \mu \mathrm{m}$ PVDF membrane is experimentally investigated. The decline of filtrate flux as function of time is analysed using the framework of classical and combined blocking models. The results for both plasmids indicate a transition between fouling mechanisms. Initially, during early part of the filtration, the intermediate blocking model provided the best fit of the experimental results suggesting that fouling of the membrane was mainly caused by deposition of particles onto its surface. Afterwards, the result trends were best captured by the standard blocking model indicating that internal fouling of membrane was the dominant fouling mechanism. A study of the transmission (Cf / C0) of both plasmids shows a significant reduction of plasmid transmission which coincides with the transition of the fouling mechanism from intermediate to standard blocking. The study highlights how the fouling behaviour of large plasmid DNA during sterile filtration is determined by the complex interplay between the flexibility of the molecules and the internal structure of the membrane. 

Application of filtration blocking models to describe fouling and transmission of large plasmids DNA in sterile filtration Affaro Affandy ${ }^{1,3}$, Eli Keshavarz-Moore ${ }^{1}$, Henk K. Versteeg ${ }^{2+}$

${ }^{1}$ The Advanced Centre for Biochemical Engineering, University College London, Torrington Place, London WC1E 7JE, United Kingdom. ${ }^{2}$ Healthcare Engineering, Wolfson School of Mechanical and Manufacturing Engineering, Loughborough University, Loughborough, United Kingdom. ${ }^{3}$ Department of Biotechnology, Kuliyyah of Science, International Islamic University Malaysia, Malaysia.

\section{Abstract}

Sterile filtration is considered as a final step in processing pharmaceutical grade plasmid DNA. During the development of the filtration process, fundamental understanding on the mechanism of fouling is critical to improve filtration operations. The mechanism of fouling of pQR150 (20 $\mathrm{kb}$ ) and pGEc47 (56 kb) plasmids DNA during constant pressure filtration inside $0.22 \mu \mathrm{m}$ PVDF membrane is experimentally investigated. The decline of filtrate flux as function of time is analysed using the framework of classical and combined blocking models. The results for both plasmids indicate a transition between fouling mechanisms. Initially, during the early part of the filtration, the intermediate blocking model provided the best fit of the experimental results suggesting that fouling of the membrane was mainly caused by deposition of particles onto its surface. Afterwards, the result trends were best captured by the standard blocking model indicating that internal fouling of the membrane was the dominant fouling mechanism. A study of the transmission of both plasmids shows a significant reduction of plasmid transmission which coincides with the transition of the fouling mechanism from intermediate to standard blocking. The study highlights how the fouling behaviour of large plasmid DNA during sterile filtration is

${ }^{\dagger}$ Corresponding author. Email address: h.k.versteeg@lboro.ac.uk 
1 determined by the complex interplay between the flexibility of the molecules and the internal

2 structure of the membrane.

3 Keywords: Sterile filtration, plasmid DNA, fouling, blocking models, filtration law

\section{1. Introduction}

5 Current progress in gene therapy and DNA vaccination has increased demand for and interest

6 in plasmid DNA. At present, four DNA vaccine and gene therapy products have been licensed

7 for veterinary use [1]. The processing of non-viral DNA for gene therapy and vaccination has

8 been reviewed widely and this involves several unit processes [2-6]. This article is focused on

9 the sterile filtration step which typically constitutes one of the final stages in the production of 10 therapeutic grade DNA. While there is general consensus that the study of this processing step 11 is of paramount importance, relatively little systematic work has been done in the area. A 12 particular concern is the issue of product loss related to fouling of the membrane. A recent study 13 by Kong et al (2006) [7] has shown that plasmid filtration through $0.22 \mu \mathrm{m}$ filter resulted in 14 losses of up to $80 \%$ for $116 \mathrm{~kb}$ naked DNA. The result suggested an increase of losses of DNA when the molecular size of plasmid increases.

16 At present, small plasmids (less than $20 \mathrm{~kb}$ ) have been used in gene therapy and DNA 17 vaccination. The application of large plasmids may become critical in the future to enable 18 specific therapeutics applications which require large pieces of genetic information. Examples are the demand of multi-genes for certain therapeutic purposes and incorporation of cytokines

20 for the enhancement of immune response of encoded antigens [8].

21 Fouling is the blockage or retention of impurities or product of interest onto the surface of or inside the membrane. It affects the quality and transmission of the desirable product. One of strategies to investigate these interactions is by direct visualisation method using various 
1 microscopy techniques [9-11]. However, microscopy techniques are unable to supply real time

2 information of the filtration process. Besides the preparation of samples is labour intensive and

3 time consuming.

4 The progress of fouling during constant pressure filtration can also be characterised by

5 mathematical analysis of flux decline during filtration. By employing filtration blocking models,

6 firstly the mechanism of fouling and secondly the transition of the progress of fouling in the filter

7 can be determined. Conventional filtration blocking models have been widely applied to

8 investigate fouling mechanisms and to predict the capacity of membranes which is critical for

9 filter scale-up. Four classical filtration models describe the mechanism of fouling during particle

10 filtration through the following mechanistic models: (i) standard blocking (gradual pore

11 constriction), (ii) complete blocking (sealing of pore entrances), (iii) intermediate blocking

12 (sealing and accumulation on membrane surface) and (iv) cake filtration blocking models [12].

13 Combinations of these models were later developed to account for more complex fouling

14 mechanisms during filtration [13-15]. Table 1 summarises the equations governing the filtrate

15 volume collected as a function of time for each model. In these equations, $V$ is the filtrate

16 volume $\left(\mathrm{m}^{3}\right), V_{0}$ is the initial volumetric flow rate $\left(\mathrm{m}^{3} / \mathrm{s}\right), A_{0}$ is the initial membrane frontal area

$17\left(\mathrm{~m}^{2}\right), t$ is time (s) and $k_{s}, k_{i}, k_{b}, k_{c}$, and $k_{i c}$ are fouling parameters. 
Standard blocking [16]

$$
V=\left(V_{0} t\right)\left(1+\frac{k_{s} V_{0}}{A_{0}} t\right)^{-1} \quad k_{s}\left(\mathrm{~m}^{-1}\right)
$$

Intermediate blocking [16]

$$
V=\frac{1}{k_{i}} \ln \left(1+k_{i} V_{0} t\right)
$$

Complete blocking [16]

$$
V=\frac{V_{0}}{k_{b}}\left[1-\exp \left(-k_{b} t\right)\right]
$$

$$
k_{b}\left(\mathrm{~s}^{-1}\right)
$$

Cake filtration [16]

$$
V=\frac{1}{V_{0} k_{c}}\left(\sqrt{1+\left(2 k_{c} V_{0}^{2} t\right)}-1\right)
$$

$k_{c}\left(\mathrm{~s} . \mathrm{m}^{-6}\right)$

Intermediate-standard [13] $\quad V=\frac{A_{0}}{k_{i c}} \ln \left(1+\frac{2 k_{i c}\left(V_{0} / A_{0}\right) t}{2+k_{s}\left(V_{0} / A_{0}\right) t}\right) \quad k_{i c}\left(\mathrm{~m}^{-1}\right)$ and $k_{s}\left(\mathrm{~m}^{-1}\right)$

$$
\text { Complete-standard [13] } \quad V=\frac{V_{0}}{k_{b}}\left(1-\exp \left(\frac{-2 k_{b} t}{2+k_{s}\left(V_{0} / A_{0}\right) t}\right)\right) \quad k_{b}\left(\mathrm{~s}^{-1}\right) \text { and } k_{s}\left(\mathrm{~m}^{-1}\right)
$$

Table 1- Summary of classical and combined blocking models for constant transmembrane pressure

3 In cases where transition of fouling and the operative particle retention mechanisms take place

4 during filtration, this can be estimated by using the following mathematical form $[14,17,18]$ : 


$$
\frac{d^{2} t}{d V^{2}}=k\left(\frac{d t}{d V}\right)^{n}
$$

Equation 1

1 Equation 1 expresses the rate of variation of the instantaneous resistance to filtration in term of

2 a power law function of the instantaneous resistance. The parameter $k$ in Equation 1 is the

3 filtration constant. The exponent $n$ characterises the fouling mechanism; it can be shown that

$4 n=0$ corresponds to cake filtration, $n=1$ for intermediate blocking, $n=1.5$ for standard blocking

5 and $n=2$ for complete blocking [12]. Changes to the value of $n$ during filtration indicate more

6 complex fouling mechanisms that are more accurately captured by one of the combined models.

7 The investigation of the mechanism of fouling is important in defining optimum filtration

8 condition; in terms of process parameters, product-membrane interactions and optimisation of

9 numerous membrane attributes such as pore architecture. The filtration blocking model is also

10 applied to predict the maximum volumetric capacity $\left(V_{\max }\right)$ of a membrane $[15,19]$. Therefore,

11 an accurate determination of the specific model that describes the fouling mechanism leads to

12 better sizing prediction during scaling up of filtration.

13 Before we can apply the filtration blocking models, it is important to understand the dominant

14 fouling mechanism. However, the above models have their limitations due to inherently simple 15 assumptions relating to the filter and particulate characteristics. The filter is assumed to consist 16 of cylindrical pores whereas actual membranes exhibit highly interconnected, tortuous flow 17 passages [15]. The feed is assumed to contain a suspension of hard spherical particles, but 18 plasmid DNA molecules considered in this study are flexible and coiled shape structure. 19 Furthermore, the conformation and orientation of plasmids in liquid solution is dynamic and 20 influenced by fluid flow [20, 21]. Therefore the ability of these models to explain the filtration 21 behaviour of plasmid DNA, especially large plasmids, needs to be studied. 
1 This paper reports the findings of an investigation of the sterile filtration of two large plasmids

2 DNA- pQR150 (20 kb) and pGEc47 (56 kb) during constant pressure filtration with a $0.22 \mu \mathrm{m}$

3 PVDF membrane. Analysis of the flux decline using filtration blocking models provides

4 information on the specific fouling mechanism that dominates the fouling during the entire

5 course of filtration. The transmission $\left(\mathrm{C}_{\mathrm{f}} / \mathrm{C}_{0}\right)$ of the plasmids was studied in an attempt to

6 understand the connection between transmission characteristics and flux decline. The results

7 enable us to comment on the applicability of filtration blocking model to explain the fouling

8 behaviour of large plasmid DNA during sterile filtration.

\section{2. Materials and Methods}

\subsection{Plasmid and bacterial cultures}

Plasmids pQR150 (Kanamycin resistance, $20 \mathrm{~kb}$ ) and pGEc47 (Tetracycline resistance, $56 \mathrm{~kb}$ ) were used in this experiment and grown in E.coli $\mathrm{DH} 5 \mathrm{a}$ and $\mathrm{DH} 1$ respectively. The bacteria were grown on plates containing Nutrient Broth (Oxoids, Basingstoke, Hertfordshire, UK) with appropriate antibiotic. A single colony of bacteria was selected and inoculated to seed cultures of $10,50,100$ and $500 \mathrm{ml}$. The media based on Wubbolts et al [22] was used as fermentation medium for E.coli DH1 and Nutrient Broth was used to grow the DH5a.The cultures were grown at $37^{\circ} \mathrm{C}$ for 8 hours with vigorous shaking (200 rpm) for subsequent fermentation. 310 fermenter (New Brunswick, Cambridge, U.K) and Applikon 20 litres bioreactor (Applikon Biotechnology, Gloucestershire, U.K) with addition of $0.2 \%$ w/v dextran and trace elements. A

$21 \mathrm{pH}$ of $6.3 \pm 0.2$ was maintained by automatic pumping of $1 \mathrm{M}$ sodium hydroxide $(\mathrm{NaOH})$ and 1 
1 speed adjustment. To avoid foaming during fermentation, polypropylene glycol $(50 \% \mathrm{v} / \mathrm{v})$ was

2 added as an antifoaming agent.

\section{$3 \quad 2.2 \quad$ Purification of plasmid DNA}

4 E. coli cells were harvested from fermentation media by Beckman J2-M1 centrifuge (Beckman5 Coulter, High Wycombe, U.K) for 30 minutes at $4000 \mathrm{rpm}$. The cell paste was then stored at $620^{\circ} \mathrm{C}$ for further use. For purification of plasmid DNA, the cells were dissolved with resuspension 7 buffer (Buffer P1) containing $50 \mathrm{mM}$ Tris-Cl (pH 8), $10 \mathrm{mM}$ EDTA and $100 \mu \mathrm{g} / \mathrm{ml}$ RNase A. The

8 cells were then treated with lysis buffer containing $200 \mathrm{mM} \mathrm{NaOH}$ and 1\% SDS (Buffer P2) for $9 \quad 2-5$ minutes. The mixture was mixed gently to degrade the bacteria cell wall and to avoid 10 degradation of SC plasmids DNA. Neutralising buffer containing $3.0 \mathrm{M}$ potassium acetate pH 115.0 (Buffer P3) was then added to precipitate proteins and other contaminants. The alkaline 12 lysis buffers P1, P2 and P3 were supplied by Qiagen (Qiagen, West Sussex, U.K). The mixture 13 was centrifuged for 5 minutes at $4000 \mathrm{rpm}$ and subsequently filtered using $47 \mathrm{~mm}$ grade 4 (20$1425 \mu \mathrm{m}$ pore size rating) cellulose filters (Whatman, Kent, U.K). The plasmid was later purified by 15 Hispeed $\mathrm{Tip}^{\mathrm{TM}}$ anion exchange column chromatography and Qiaprecipitator ${ }^{\mathrm{TM}}$ of Qiagen 16 Hispeed plasmids purification kits (Qiagen, West Sussex, U.K). The plasmid was then eluted 17 with $10 \mathrm{mM}$ Tris-EDTA buffer.

\subsection{Agarose gel electrophoresis}

19 The plasmid DNA isoforms were confirmed by agarose gel electrophoresis. $0.6 \%$ agarose gel 20 was pre-stained with $0.5 \mu \mathrm{g} / \mathrm{ml}$ final concentration of ethidium bromide. The gel was run in $1 \mathrm{X}$

21 Tris-Borate EDTA (Sigma Aldrich, Dorset, UK) at 4.5 volts/cm for 4 hours. Supercoiled DNA 22 ladder (Invitrogen, Paisley, U.K.) and BAC DNA ladder (Epicentre Biotechnologies, Cambridge, 
1 UK) were used to determine the size of plasmids. Images of the DNA bands were acquired and

2 processed with Gel Doc ${ }^{T M} E Q$ gel documentation system and Quantity One ${ }^{T M}$ gel analysis 3 software (BioRad, CA, USA). The unfiltered feed solutions of pQR150 plasmid (20 kb) had a 4 typical supercoiled (SC) content of $>80 \%$. For pGEc47 plasmid (56 kb), the SC content of 5 unfiltered feed solutions was $>50 \%$.

\section{$6 \quad 2.4 \quad$ Spectrophotometry analysis}

7 The concentration of DNA was measured using NanoDrop ${ }^{\mathrm{TM}} 2000$ spectrophotometer (Thermo 8 Scientific, DE, U.S). The purity of the DNA after purification was confirmed by analysis of 9 absorbance ratio at 260/280. The $260 / 280$ ratio was used for determination of DNA purity 10 against protein contamination; the standard ratio for plasmid purity is 1.8-2.0.

\section{$11 \quad 2.5 \quad$ Filtration experiments}

12 Normal flow filtrations were performed using a syringe filter unit equipped with sterilising grade $1313 \mathrm{~mm}$ Millex ${ }^{\mathrm{TM}} /$ Durapore $^{\circledR} 0.22 \mu \mathrm{m}$ polyvinylidene fluoride (PVDF) membrane (Millipore, MA, 14 USA). The filter unit was affixed to an Amicon Stirred Cell 8300 (Millipore, M.A., U.S) connected 15 to $\mathrm{N}_{2}$ source. The pressure drop during the filtration was measured using Millipore Integrity Test 16 kits (Millipore, MA, US). The illustration of the filtration configuration is presented in Figure 1.

17 The plasmid DNA samples used in these experiments were pre-filtered with $0.22 \mu \mathrm{m}$ membrane 18 before the constant pressure filtration at 5 and 8 psi transmembrane pressures. The total filtrate 19 volume for each filtration experiment is approximately $5 \mathrm{ml}$. All the experiments were performed 20 at room temperature. 
1 The experimental data was acquired by collecting filtrate volumes in a specific time interval. The

2 filtrates were collected with collection tubes and an electronic balance was used to measure the

3 filtrate weight. The results shown in each plots are average of two or three experiments.

4

5

6

9

10

11

12

13

14

15

16 To investigate the transition of fouling mechanism during filtration, the filtrate flux data was

17 analysed in term of $d^{2} t / d V^{2}$ versus $d t / d V$ as suggested in Equation 1. The derivatives $d t / d V$ and

Figure 1- Illustration of a sterile filtration configuration. $(\mathrm{V})$ valve, $(\mathrm{P})$ pressure meter, $(\mathrm{T})$ tank, $(\mathrm{F})$ filter.

\subsection{Non-linear regression analysis}

To analyse the fouling mechanism of plasmids pQR150 (20 kb) and pGEc47 (56 kb), the experimental filtration data was initially fitted with the classical blocking models (standard, intermediate, complete and cake filtration blocking models) using non-linear regression tool of the SigmaPlot statistical and graphing package (Systat Software, London, U.K). The experimental data was subsequently fitted with combined filtration blocking models developed by Bolton et al (2006) [13] to determine whether the combination of classical models can provide better fit with the experimental data. The non-linear regression works by minimizing the sum of square residuals of the data points from the curve of the models.

\subsection{Power law fouling transition analysis}

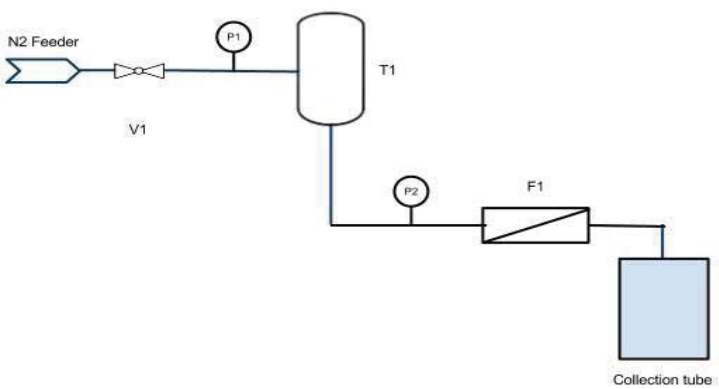


$1 d^{2} t / d V^{2}$ were computed by taking the analytical derivatives of the best fit functions (Table 1).

2 The values of $d t / d V$ were obtained by reciprocal of the derivatives of filtrate volume vs. time plot $3(d V / d t)$

$$
\frac{d t}{d V}=\frac{1}{d V / d t}
$$

4 And the derivative of $d^{2} t / d V^{2}$ was obtained by:

$$
\frac{d^{2} t}{d V^{2}}=\frac{d}{d V}\left(\frac{d t}{d V}\right)=\frac{d t}{d V} \times \frac{d}{d t}\left(\frac{d t}{d V}\right)
$$

5 The power law coefficient, $n$ was obtained by taking logarithms on both sides of power law

6 Equation 1 followed by a linear regression to yield the following form:

$$
\log \left(d^{2} t / d V^{2}\right)=n * \log (d t / d V)+C \quad \text { Equation } 4
$$

7 The average values of $\mathrm{n}$ during early, mid and late time of filtration of pQR150 (20 kb) and 8 pGEc47 (56 kb) plasmids at 5 and 8 transmembrane pressures was estimated using Equation 94.

10 The transformation of the values of $n$ was then estimated by differentiating the logarithm of $11 d^{2} t / d V^{2}$ with respect to the logarithm $d t / d V$ :

$$
n=\frac{d\left[\log \left(d^{2} t / d V^{2}\right)\right]}{d[\log (d t / d V)]}
$$




\section{$1 \quad 2.8 \quad$ Transmission analysis of filtrate}

2 The transmission of plasmid during filtration is expressed by the ratio of DNA concentration of

3 the filtrate over initial DNA concentration $\left(C_{A} / C_{0}\right)$. The concentration of plasmid DNA was

4 detected using the method explained in subsection 2.4. To obtain the concentration of filtrate at

5 a specific time during the filtration, the filtrates were collected in batches. During the early

6 stages of filtration (1-3 minutes) samples were collected every 10 seconds. Afterwards and

7 towards the end of filtration samples were taken at 2 minutes intervals. This compensates for

8 the low filtrate flux towards at the end of the filtration which requires sampling duration to 9 increase. 


\section{Results and Discussion}

\section{$2 \quad 3.1 \quad$ Characterisation of plasmid DNA sample}

3 The absorption property of DNA is used to assess the quality of plasmid DNA during the

4 filtration. The absorbance ratio at $A_{260} / A_{280}$ of both $p Q R 150$ and $p G E c 47$ fall between1.8-2.0 5 which suggests acceptable purity of DNA against protein contamination. Furthermore, the 6 absorbance ratio at $A_{260} / A_{230}$ was also used as a secondary measurement of DNA purity against salts and organic compounds contamination. All samples used in this experiment fall within the acceptable range of $A_{260} / A_{230}$ which is between 1.5-1.8. The characterisation of plasmid DNA samples using agarose gel electrophoresis showed that the plasmid is free from genomic DNA and RNA.

\subsection{Analysis of fouling transition during filtration of plasmid DNA}

In order to obtain understanding of the process of fouling, mathematical analysis has been performed to investigate the transition of fouling mechanism. Figure 2 illustrates the results of the power law analysis by means of log-log Equation 4. The slope of the line increases as log $(d t / d V)$ increases, which corresponds to increasing time $t$. Since the slope of this line is equal to power law exponent $n$ in Equation 1, the results indicate that a transition of the dominant fouling mechanism takes place during 8 psi transmembrane pressure filtration of pQR150 (20 kb) and pGEc47 (56 kb). A similar trend was observed during the filtration of both plasmids at 5 psi. The transition of the average value of $n$ that describes the fouling behaviour during early, mid and late time filtration is extracted from these plots. Figure 3 contains information relating to the

21 dominant fouling mechanism at a specific time during filtration in simplified form. 
1 The common feature of all the results is that early on in the filtration, the exponent $n$ originates

2 from a value that closes to 1 . This implies that during this stage, intermediate blocking model 3 dominates the fouling, so plasmids are initially retained on the surface of membrane. Later on, 4 the values of $n$ seem to approach $n \sim 1.5$ asymptotically. This value suggests that the fouling is 5 dominated by the standard blocking model where the internal fouling occurred within the depth 6 of the filter.

7 Figure 3 describes that during the filtration at 8 psi, the transition of the value of $n$ (from low to 8 high $n$ values) occurred earlier (at low $d t / d V$ ) for pQR150 (20 kb) than pGEc47 (56 kb). This is 9 expected since the smaller size of pQR150 (20 kb) allows the plasmid to penetrate the 10 membrane efficiently. 

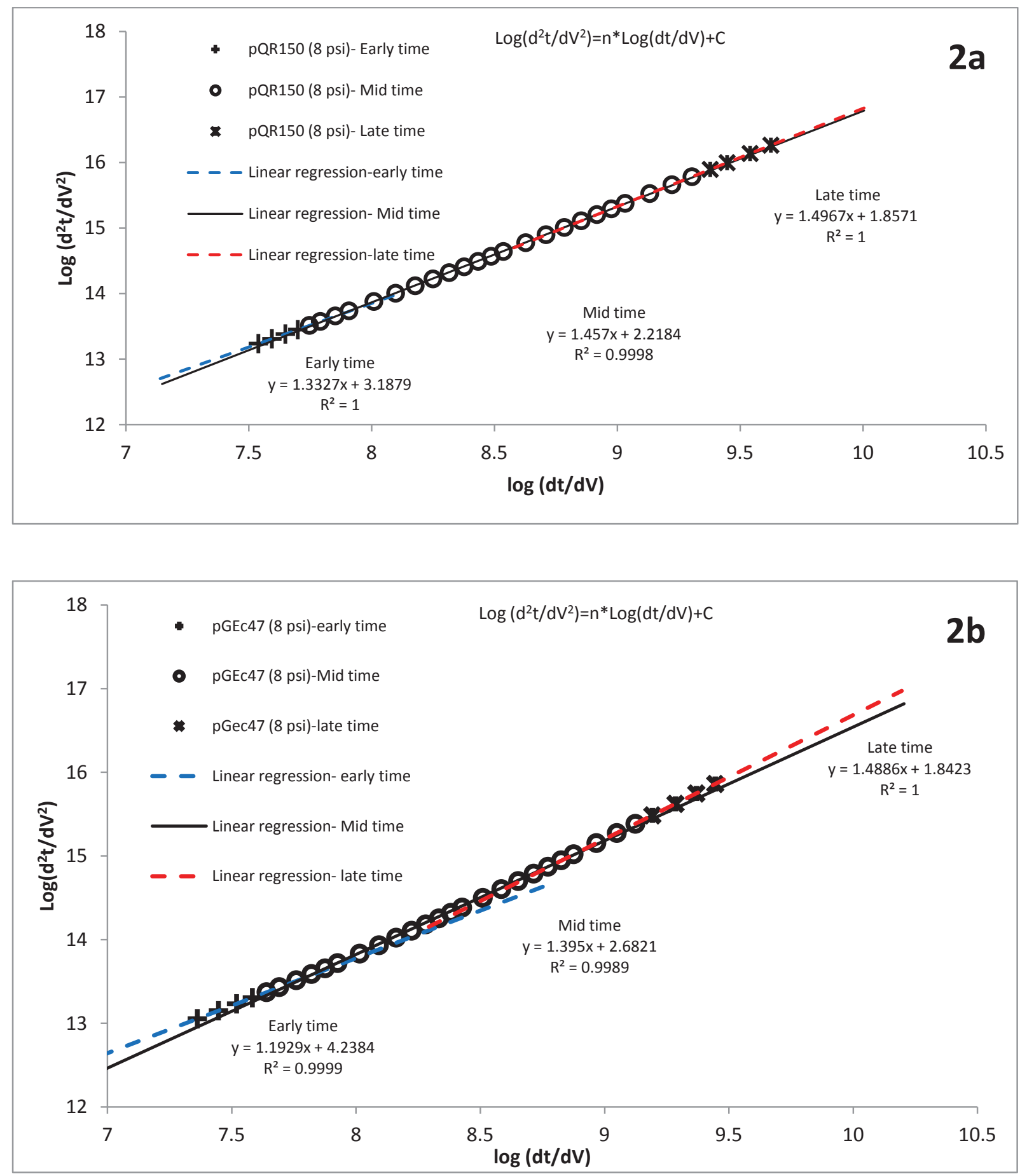

3 Figure 2- Flux decline analysis of pQR150 (20 kb) and pGEc47 (56 kb) filtrations at 8 psi transmembrane 4 pressure. 


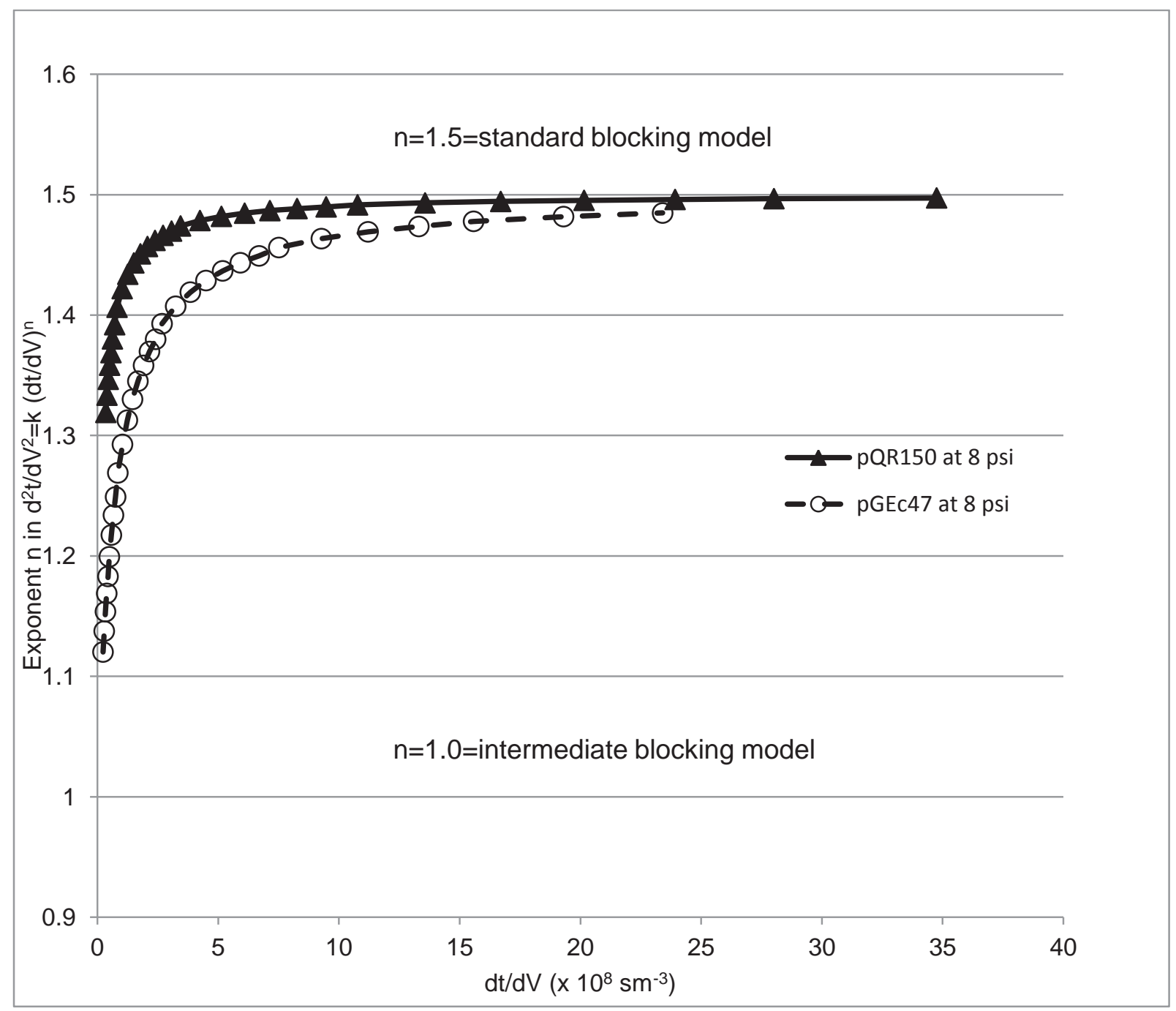

2 Figure 3 - The plot of exponent $n$ (Equation 1) vs. $d t / d V$ of the filtration of pQR150 (20 kb) and pGEc47 (56 kb) at 8 psi transmembrane pressure.

4 The filtration behaviour of DNA is different from protein and other particulates since DNA is a 5 flexible long chain molecule. These characteristics allow DNA to penetrate the pores and 6 elongate during the passage through the membrane. Furthermore, large DNA molecule with 7 radii of gyration that is larger than the nominal pore size can potentially be retained inside the 8 interstitial pore structure. It is possible that during its trajectory through the membrane, 
entrapment of a plasmid occurs at the surface of pore and at the same time the other parts of a

2 plasmid penetrate along the web of the other pores.

3 The interesting feature of the present results is that the transformation of the values of $n$

4 contrasts with results observed during the microfiltration of particulate suspensions; such as

5 filtration of bovine serum albumin (BSA), which, like other proteins, can be successfully

6 modelled as rigid and sphere-shaped molecule [23]. BSA is a type of protein with a diameter

7 typically smaller than the nominal size of pores in microfiltration membrane [24]. Retention of

8 BSA was observed inside the inner wall of the pore and could be characterised using the

9 standard blocking model [25]. Other work has also shown that the fouling of BSA aggregates

10 occurred on the surface of membrane [26]. Iritani and co-workers [17] reported during the

11 filtration of BSA through $0.05 \mu \mathrm{m}$ nitrocellulose membrane, the values of $n$ were maximum at the

12 initial stage of filtration (low $d t / d V$ ) and decreased to 0 as the cake occurred at the end of

13 filtration.

14 Interestingly, during the filtration of pQR150 (20 kb) and pGEc47 (56 kb) plasmids, the values of $15 n$ increased with the increase of $d t / d V$ until it approached asymptote around 1.5 that represents 16 the standard blocking mechanism. The value of $n$ at early time filtration is close to 1 ; indicating 17 the intermediate blocking model dominated the fouling mechanism at this stage. The results 18 suggested that at the beginning of the filtration, plasmids DNA were trapped as its chain-like 19 molecule did not align with the surface of membrane. It is also thought that the trajectory and 20 orientation of plasmids is initially parallel with the surface of the filter. Since plasmids are 21 flexible, the molecule can realign its structure to penetrate the pore with the assistance of shear 22 stress originating from flow of the solution inside the membrane [27]. 
1 However, it should be noted that the usefulness of this analysis, i.e. the statistical precision of

2 the values of $n$ in Figures 2 and 3 is strongly depends on the goodness of fit of the expressions

3 used in Table 1 and the original volume-time data. As explained in subsection 2.7, the

4 derivatives of $d t / d V$ and $d^{2} t d V^{2}$ were computed by taking the analytical derivatives of the best fit

5 functions. It is worth to mention that small discrepancies between the volume-time data and the

6 best fit curve could amplify errors between actual derivatives of $d t / d V$ and $d^{2} t / d V^{2}$. As our

7 interest is in the change of the power law constants, it is possible to control such errors to some

8 extent by repeating the best fit analysis on subsets of the data.

\section{$9 \quad 3.3 \quad$ Analysis of fouling using classical filtration blocking models}

The objectives of this study are to determine whether the classical filtration blocking models can explain the fouling phenomena of large plasmids DNA and to find out the operative retention mechanism of the fouling; i.e. whether a single or combination of fouling mechanisms exists.

In performing the non-linear regression, the initial volumetric flow rate, $V_{0}\left(\mathrm{~m}^{3} / \mathrm{s}\right)$, initial membrane frontal area; $A_{o}\left(\mathrm{~m}^{2}\right)$, and blocking constants; $k_{s}, k_{i}, k_{b}, k_{c}$, and $k_{i c}$ are the required constant parameters. The blocking constant was determined numerically while $V_{0}$ was obtained from experiments and $A_{0}$ is based on specification supplied by the manufacturer. Therefore, only one parameter was determined numerically by the software which is important to narrow the confidence interval of the plots.

The flux decline analysis of $d^{2} t / d V^{2}$ vs. $d t / d V$ shows that the values of $n$ vary from $\sim 1$ to 1.5 which suggest that the transition of fouling is between intermediate $(n=1)$ and standard $(n=1.5)$ blocking models. We only test these two models since the experimental data of $n$ is neither close to cake filtration $(n=0)$ nor complete blocking model $(n=2)$. 
1 The experimental data were then fitted with standard and intermediate blocking models to 2 investigate the ability of these models to describe the flux decline phenomena during the 3 filtration of pQR150 (20 kb) and pGEc47 (56 kb) at 5 and 8 psi transmembrane pressures. 4 Figure 4 shows the experimental data and model predictions for pQR150 and pGEc47 at 5 and 58 psi transmembrane pressures.

6 Imperfect agreement between the predictions of the classical blocking models and experimental 7 data can be observed in Figure 4. The closeness of the model curves to the experimental data 8 was quantified by means of the standard error of estimates (Table 2). 

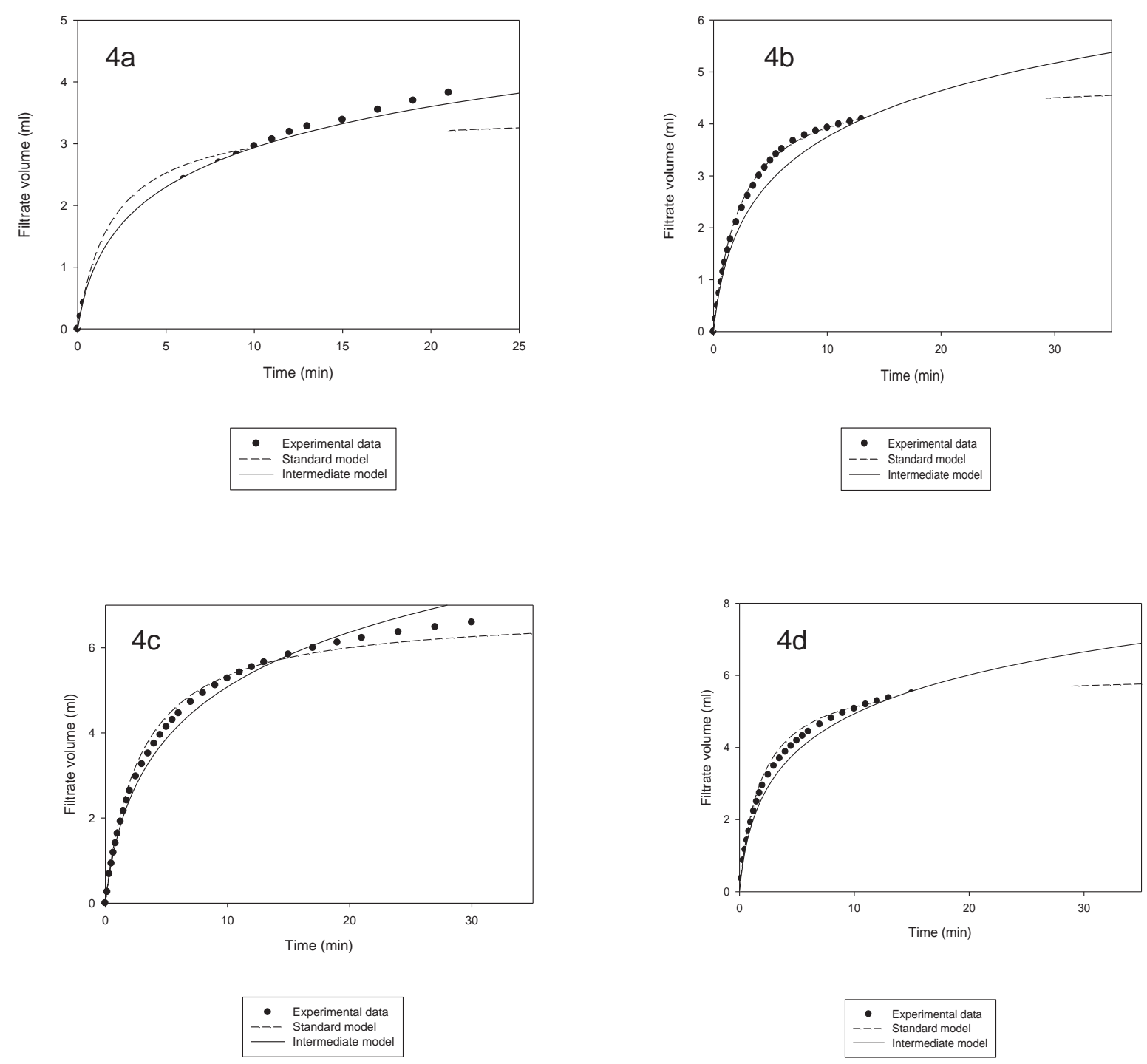

3 Figure 4 - Experimental data of filtrate volume vs. time fitted with the standard and intermediate blocking 4 models. Solution containing $50 \mu \mathrm{g} / \mathrm{ml}$ of plasmid was filtered through $0.22 \mu \mathrm{m}$ PVDF membrane. Figure 4a represents pQR150 (20 kb) at 5 psi, 4b) pQR150 (20 kb) at 8 psi, 4c) pGEc45 (56 kb) at 5 psi and 4d) pGEc47 (56 kb) at 8 psi transmembrane pressure. 


\begin{tabular}{llcc}
\hline Plasmid & Model & Standard error of estimates & Standard error of estimates \\
& & $5 p s i$ transmembrane pressure & 8psi transmembrane pressure \\
\hline pQR150 & Standard & 0.325 & 0.078 \\
& Intermediate & 0.120 & 0.272 \\
\hline pGEc47 & Standard & 0.191 & 0.342 \\
& Intermediate & 0.221 & 0.198 \\
\hline
\end{tabular}

Table 2 - Standard error of estimates of the filtration of pQR150 $(20 \mathrm{~kb})$ and pGEc47 $(56 \mathrm{~kb})$ at 5 and 8

psi.

3 The results suggested that the classical blocking models were unable to describe the flux

4 decline during the entire course of filtration of pQR150 (20 kb) and pGEc47 (56 kb) plasmids as

5 intermediate or standard blocking models could only describe parts of the filtrate volume vs.

6 time (Figure 4). For example, the filtration of pQR150 (20 kb) at 8 psi transmembrane pressure

7 showed that the best fit occurred with the standard model during the first 20 minutes of filtration.

8 Furthermore, the best fit of the experimental data of pGEc47 (56 kb) occurred with intermediate

9 model but only for the first 5 minutes of filtration.

10 The results of the filtration of large plasmids $(>20 \mathrm{~kb})$ contrast with the filtration of small plasmid 11 (6 kb) which followed the standard blocking model with a very good fit of $R^{2}>0.9999$ [28]. The 12 mechanism of fouling of large plasmid DNA is different from the behaviour shown in smaller size 13 plasmid. Due to its smaller size, the latter will easily pass through the membrane as the plasmid 14 capable to align and deform more quickly into the direction of the flow, whereas large plasmid 15 DNA molecule has a higher tendency to deposit on the surface of membrane. This lends 16 support to the finding by Kong et al (2006) that the transmission of plasmids DNA depends on 17 its molecular weight [7]. 


\section{$1 \quad 3.4 \quad$ Analysis of fouling using combined blocking models}

2 The test results suggested that the fouling mechanism of large plasmid DNA was not governed

3 by a single fouling mechanism as described by the classical blocking models. Therefore, we

4 tested the filtration data with the combined blocking models as described by Bolton et al. (2006);

5 These authors discovered that the application of combination of these classical models in sterile

6 filtration of Immunoglobin $\mathrm{G}$ ( $\lg G$ ) and virus filtration of bovine serum albumin (BSA) led to

7 better fit of the experimental data [13]. The idea is to combine the classical blocking models

8 (i.e. combination of standard and intermediate models) and determine if a transition of fouling

9 mechanisms exists during filtration. Originally, five combined blocking models were proposed:

10 intermediate-standard, complete-standard, cake-standard, cake-intermediate and cake-

11 complete models. The selection of candidates of combined blocking models was based on the

12 values of $n$ in the $d^{2} t / d V^{2}$ vs. $d t / d V$ which suggest that the standard and intermediate models

13 closely fit the experimental data. Moreover, the last four combined models were ignored

14 because the blocking models other than the standard and intermediate models consistently

15 yielded a poor fit of the data. Thus only the intermediate-standard model was considered for 16 explaining the fouling mechanism of the filtration of pQR150 (20 kb) and pGEc47 (56 kb) 17 plasmids DNA. Figure 5 shows the experimental result of the filtration test of pQR150 (20 kb) and pGEc47 (56 kb) at 5 and 8 psi transmembrane pressures and the corresponding best-fit

19 lines for the intermediate-standard blocking model. The best fit of data occurred with the

20 filtration of pGEc47 (56 kb) at 5 and 8 psi. Similar trends and levels of agreement between data

21 and combined blocking model were observed with the other filtration tests. 

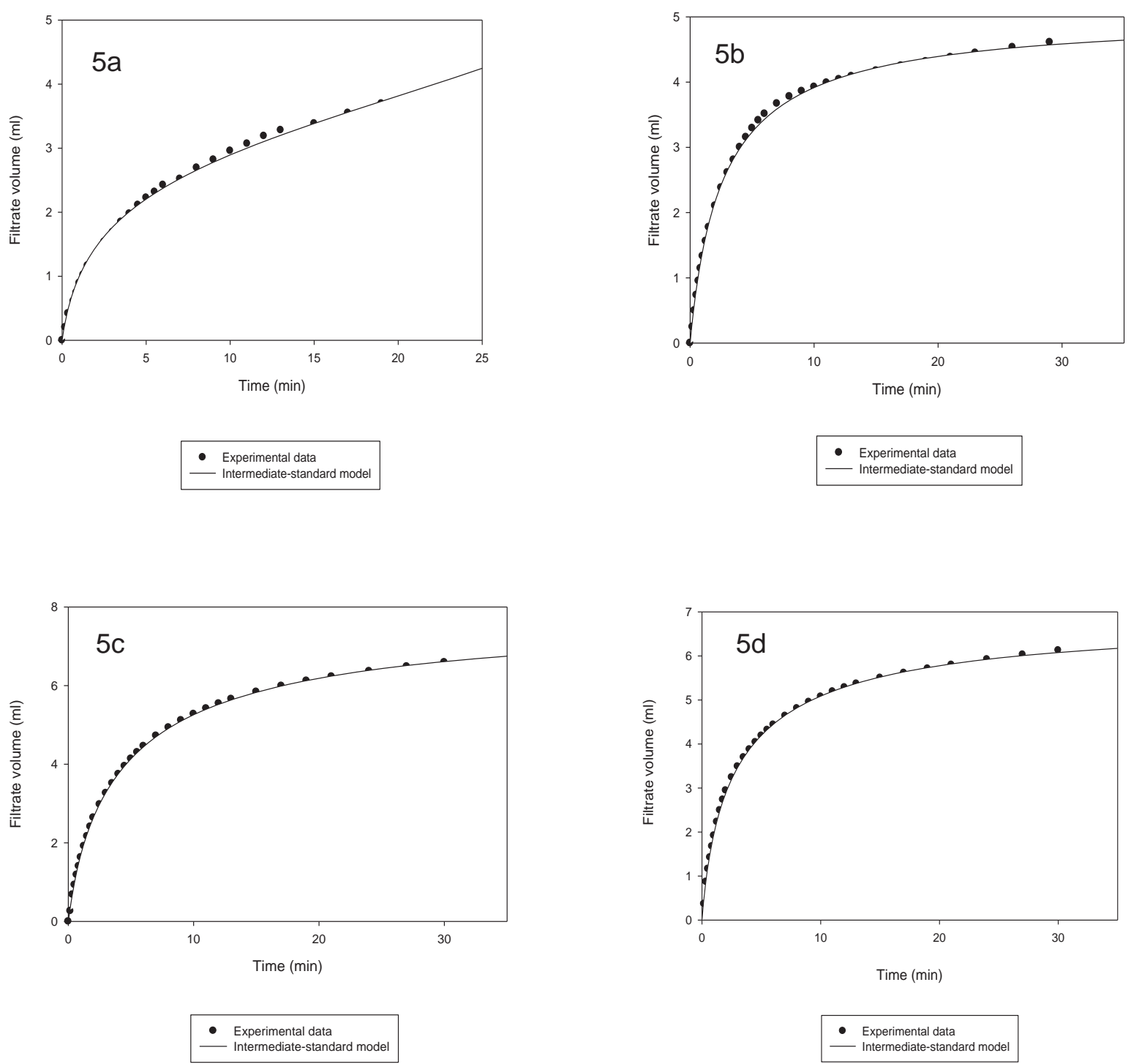

3 Figure 5- Experimental data of filtrate volume vs. time fitted with the intermediate-standard blocking 4 model. Solution containing $50 \mu \mathrm{g} / \mathrm{ml}$ of plasmid was filtered through $0.22 \mu \mathrm{m}$ PVDF membrane. Figure 4a represents pQR150 (20 kb) at $5 \mathrm{psi}, 4 \mathrm{~b}) \mathrm{pQR} 150(20 \mathrm{~kb})$ at $8 \mathrm{psi}, 4 \mathrm{c})$ pGEc45 (56 kb) at 5 psi and 4d) 6 pGEc47 (56 kb) at 8 psi transmembrane pressure. 


\begin{tabular}{llcc}
\hline Plasmid & Model & $\begin{array}{c}\text { Standard error of estimates } \\
\text { 5 psi transmembrane } \\
\text { pressure }\end{array}$ & $\begin{array}{c}\text { Standard error of estimates } \\
8 \text { psi transmembrane } \\
\text { pressure }\end{array}$ \\
\hline pQR150 & Intermediate-standard & 0.077 & 0.061 \\
pGEc47 & Intermediate-standard & 0.035 & 0.165 \\
\hline
\end{tabular}

Table 3 - The model fit errors of the filtration of pQR150 and pGEc47 at 5 and 8 psi transmembrane pressures.

\begin{tabular}{lcccc}
\hline \multirow{2}{*}{ Plasmid } & \multicolumn{2}{c}{$\begin{array}{c}\text { psi transmembrane } \\
\text { pressure }\end{array}$} & \multicolumn{2}{c}{$\begin{array}{c}\text { psi transmembrane } \\
\text { pressure }\end{array}$} \\
\cline { 2 - 5 } & $k_{i c}\left(\mathrm{~m}^{-1}\right)$ & $k_{s}\left(\mathrm{~m}^{-1}\right)$ & $k_{i c}\left(\mathrm{~m}^{-1}\right)$ & $k_{s}\left(\mathrm{~m}^{-1}\right)$ \\
\hline pQR150 & 62.14 & 4.10 & 30.51 & 16.75 \\
pGEc47 & 35.68 & 4.72 & 43.44 & 4.66 \\
\hline
\end{tabular}

3 Table 4- The fouling parameters of the filtration of pQR150 and pGEc47 at 5 and 8 psi transmembrane

5 The goodness of fit of the regression equations was again quantified by means of the standard

6 error of estimate. Results in Table 3 show that the intermediate-standard model is the best model that described fouling during filtration of pQR150 $(20 \mathrm{~kb})$ and pGEc47 (56 kb) plasmids.

8 Comparison with Table 2 shows that improvement of the goodness of fit is obtained by 9 application of this combined blocking model. This suggests that the fouling process cannot be 10 described as a single mechanism but as a combination of multiple fouling mechanisms. For 11 future reference we have given Table 4, the best fit constants for the intermediate-standard models that describe the fouling in the four filtration experiments. The intermediate-standard 13 blocking model is superior to the classical blocking model, i.e. the intermediate and standard 14 blocking models as the model fit errors are smaller for the combined model. 


\section{$1 \quad 3.5 \quad$ Impact of fouling on transmission of plasmids DNA}

2 Figures 6 and 7 describe the relationship between the dominant fouling mechanisms and 3 plasmid transmission. The values of exponent $n$ in Figure 3 were re-plotted in term of

4 accumulated filtrate volume to simplify the analysis of fouling behaviour. This analysis is an 5 attempt to correlate the mathematical analysis; which is applied to calculate the values of $n$, with 6 the plasmid transmission data collected in the laboratory.

7 The transmission of both plasmids was high; $>80 \%$ during the filtration of the first 3.5 and 5.0 $8 \mathrm{ml}$ of filtrates for pQR150 (20 kb) and pGEc47 (56 kb) respectively (Figures 6a and 7a). 9 However, a significant reduction of plasmid transmission was observed afterwards, with considerable differences for the filtration of pQR150 $(20 \mathrm{~kb})$ at $5 \mathrm{psi}$. The results also suggest

11 that higher pressure filtration (at 8 psi) slightly increased the transmission of plasmids compared 12 with the filtration operated at 5 psi before the significant drop of the transmission occurred. The observation is supported by the analysis by Hirasaki et al. (1995) that showed that the increased in transmembrane pressure assisted the penetration of plasmid molecule into the pore [27].

15 However, the operation at 8 psi increases the rate of fouling by increasing the flux towards the membrane. This is observed by rapid decline of filtrate flux during filtration at 8 psi compared with the filtration at 5 psi transmembrane pressure. 

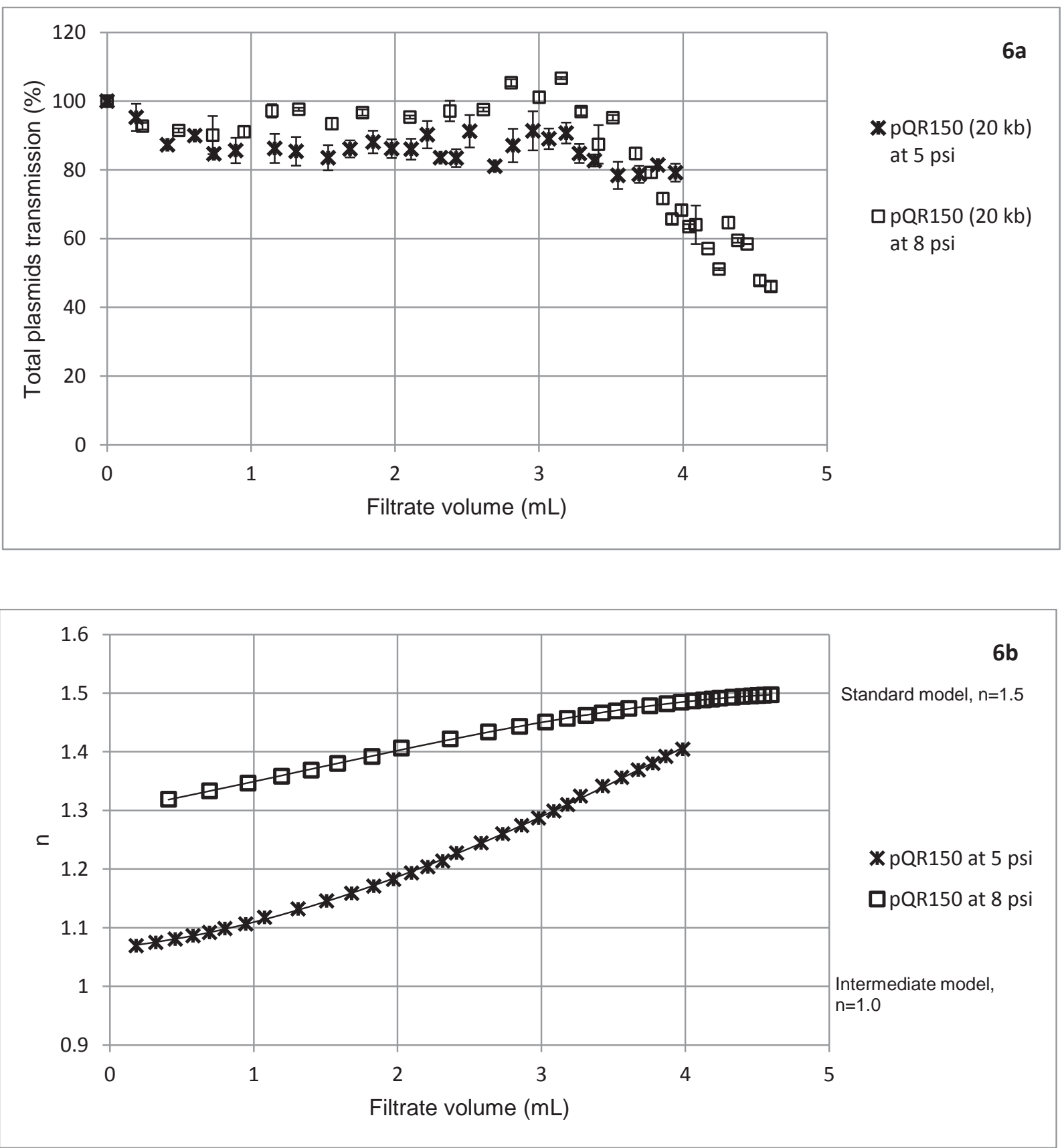

3 Figure 6- The transmission of pQR150 (20 kb) through $0.22 \mu \mathrm{m}$ PVDF membranes at 5 and 8 psi

4 constant pressure filtration. The plasmids were collected in batches and the total transmission was 5 determined by the ratio of concentration of filtrate to the concentration of feed. Error bars in Fig $6 a$ 6 indicate the standard deviation. 

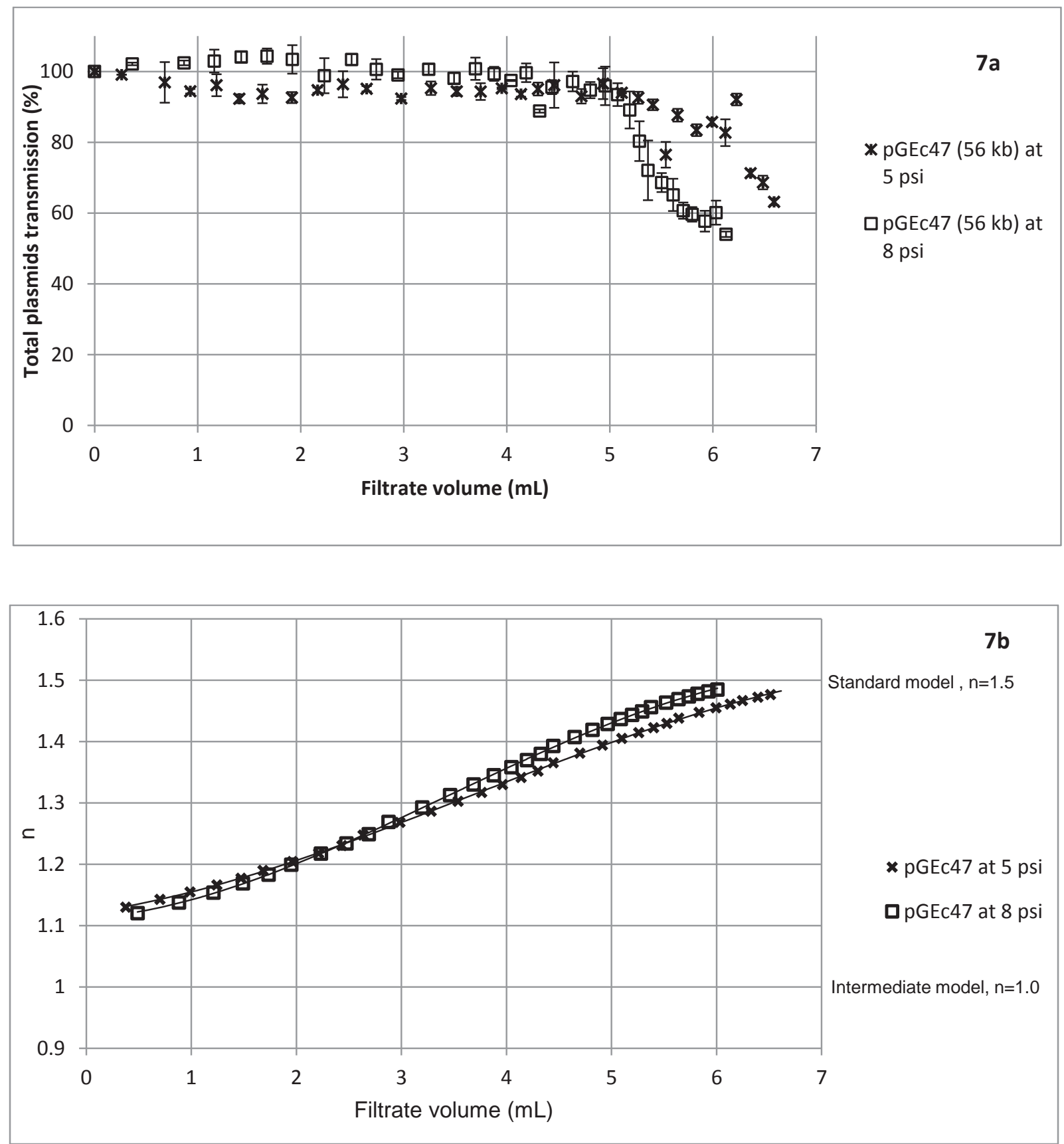

3 Figure 7- The transmission of pGEc47 (56 kb) through $0.22 \mu \mathrm{m}$ PVDF membranes at 5 and 8 psi constant

4 pressure filtration. The plasmids were collected in batches and the total transmission was determined by 5 the ratio of concentration of filtrate to the concentration of feed. Error bars in Fig 7a indicate the standard 6 deviation. 
1 During the filtration of pQR150 at $8 \mathrm{psi}$, the transmission began to drop (after filtering $\sim 3.7 \mathrm{ml}$

2 filtrates) during the point where the values of $n=1.48$ which indicates that the blocking 3 mechanism tends to the standard blocking model (Figures $6 \mathrm{a}$ and $6 \mathrm{~b}$ ). The results suggested 4 that at this point, internal fouling started to dominate the filtration and influenced the reduction of 5 internal pore diameters and consequently reduced the transmission of plasmids.

6 Similar trends were observed during the filtration of pGEc47 at 5 and 8 psi (Figures 7a and 7b).

7 The reduction of plasmid transmission can be correlated with the values of $n$ in $d^{2} t / d V^{2} v s$. $d t / d V$ 8 plot. During the time when the transmission started to drop at 5 and 8 psi filtration, the values of $9 n$ were detected at $\sim 1.43$ and $\sim 1.44$ respectively. Again, the significant reduction of plasmids 10 transmission correlated with the values of $n$ approaching 1.5

11 The analysis of the trend of $n$ vs. filtrate volume, in term of molecular weight shows that the drop of plasmid DNA transmission during 8 psi transmembrane pressure filtration occurred at a 13 smaller volume for pQR150 (20 kb), i.e. $3.5 \mathrm{ml}$, whereas for pGEc47 (56 kb), the drop of 14 transmission occurred at a higher filtrate volume of $5 \mathrm{ml}$. The trend can be correlated with the evolution of $n$ values which is for pGEc47 plasmid, the value of $n=1.5$ was obtained after $\sim 6 \mathrm{ml}$ of filtrate is collected, compared with the pQR150 which is around $\sim 4 \mathrm{ml}$. The results suggest that the constriction of membrane pores by plasmid as explained by standard model $(n=1.5)$ caused the drop in the plasmid transmission. The constriction of the pore throat influences the deformation and elongation of plasmid; which is the critical characteristics of the molecule to penetrate the pore. The results also suggest that besides the molecular weight [29], the

21 transmission is also influenced by the dominant fouling mechanism of DNA.

22 It is interesting to note that the transmission of plasmid DNA reduced significantly when the pore constriction blocking mechanism (standard model) dominated the fouling of the membrane. 
1 During the initial stage of filtration when the fouling was dominated by the intermediate blocking

2 mechanism, the blockage was caused by the superposition of plasmids that are trapped on the

3 surface of membrane. However, the transmission of plasmids began to decrease strongly when

4 the pore constriction mechanism started to dominate the fouling. At this stage, the reduction of

5 pore size due to the internal fouling influenced the flexibility and ability of plasmid to penetrate

6 the pore. Constriction of the internal pore structure would reduce the available space for

7 plasmid trajectory. Plasmid is a negatively charge molecule and at high fluid concentration;

8 when the space between plasmid molecules is reduced, electrostatic repulsion between

9 molecules is increased. The repulsion increases the rigidity of plasmids and will influence its 10 trajectory through the membrane. During the initial stage of filtration when high transmission of 11 plasmids was observed, the higher magnitudes of the shear and elongational stresses that occur at elevated transmembrane pressure (8 psi) can overcome this electrostatic repulsion and 13 consequently increase the flexibility of the plasmid. High flexibility of plasmid assists the 14 penetration of this molecule into pores. This hypothesis is in agreement with the transmission data of pQR150 $(20 \mathrm{~kb})$ and pGEc47 $(56 \mathrm{~kb})$ plasmids where the transmission was higher at 8 psi compared with 5 psi transmembrane pressure during the initial stage of filtration. In contrast,

17 low transmembrane pressure encourages the retention of DNA at the surface of membrane.

18 This is probably due to low velocity magnitude that gives rise to slower trajectory of plasmids leading to the entrapment of these molecules inside the membrane.

The data presented is also in agreement with Morao et al. (2011) which explained that the charged effect plays critical role in plasmid transmission during filtration. The authors describe that the excessive accumulation of DNA molecule on the surface of membrane imparts negatively charge monolayer of plasmid which reject the trajectory of other plasmid molecules near the pores [30]. 
1 The fouling of plasmid DNA as captured by the blocking models and filtration law can be

2 validated using various microscopy techniques. We intend to highlight this issue in a manuscript 3 that discusses the direct visualisation of plasmid DNA fouling.

\section{Conclusions}

5 Interestingly, the combined intermediate-standard model can be applied to describe the flux 6 decline behaviour of the filtration of large plasmid DNA even though the model was originally 7 developed to explain the filtration behaviour of rigid spherical particles. This work has

8 demonstrated that the model can also play a practical role in explaining the fouling behaviour 9 inside polymeric membrane that contains complex interconnected pores in spite of the assumption of the model that describes the membrane as parallel arrays of cylindrical pore.

11 During the filtration of both pQR150 and pGEc47 plasmids at 5 and 8 psi transmembrane pressures, it was found that the intermediate blocking model dominated the fouling during short initial filtration period (except for filtration of pQR150 at 8 psi). The standard blocking mechanism subsequently dominated the fouling for the remainder of the filtration.

The transmission of plasmids dropped significantly at a point when $n \sim 1.5$ in Equation 1 during the filtration at higher transmembrane pressure (at 8 psi compared with filtration at 5 psi). It is thought that high transmembrane pressure influenced the retention of plasmid by capturing this molecule inside the membrane. It is also interesting to note that the decreased of plasmid transmission is due to the internal fouling as suggested in $d^{2} t / d V^{2} v s$. $d t / d V$ plots. In summary, previous work reported in the literature has shown that membrane fouling due to smaller molecules (proteins or small plasmids) can be captured successfully with classical blocking models. Our work stresses the possibility of a more complex fouling behaviour during sterile filtration of larger plasmids due to their flexible nature. 


\section{$1 \quad$ Nomenclature}

$\begin{array}{lll}A_{0} & \text { Initial membrane frontal area } & \mathrm{m}^{2} \\ k_{b} & \text { Complete blocking constant } & \mathrm{s}^{-1} \\ k_{c} & \text { Cake filtration blocking constant } & \mathrm{sm}^{-6} \\ k_{i} & \text { Intermediate blocking constant } & \mathrm{m}^{-3} \\ k_{i c} & \text { Intermediate blocking constant in combined model } & \mathrm{m}^{-1} \\ k_{s} & \text { Standard blocking constant } & \mathrm{m}^{-1} \\ t & \text { Filtration time } & \mathrm{S} \\ V & \text { Filtrate volume } & \mathrm{m}^{3} \\ V_{0} & \text { Initial volumetric flow rate } & \mathrm{m}^{3} / \mathrm{s} \\ V_{\max } & \text { Maximum volumetric capacity of membrane per unit area } & \mathrm{m}^{3} / \mathrm{m}^{2}\end{array}$

\section{Acknowledgements}

3 AA would like to thank Ministry of Higher Education Malaysia and International Islamic $4 \quad$ University Malaysia for financial support.

\section{$5 \quad$ References}

6 1. Liu, M.A., Immunologic Basis of Vaccine Vectors. Immunity, 2010. 33(4): p. 504-515.

2. Prather, K.J., et al., Industrial scale production of plasmid DNA for vaccine and gene therapy: plasmid design, production, and purification. Enzyme and Microbial Technology, 2003. 33(7): p. 865-883.

3. Prazeres, D.M.F. and G.N.M. Ferreira, Design of flowsheets for the recovery and purification of plasmids for gene therapy and DNA vaccintion. Chemical Engineering and Processing: Process Intensification, 2004. 43(5): p. 609-624.

4. Levy, M.S., et al., Biochemical engineering approaches to the challenges of producing pure plasmid DNA. Trends in Biotechnology, 2000. 18(7): p. 296-305. 
5. Shamlou, P.A., Scaleable processes for the manufacture of therapeutic quantities of plasmid DNA. Biotechnology and Applied Biochemistry, 2003. 37(3): p. 207-218.

6. Carnes, A.E. and J.A. Williams, Plasmid DNA Manufacturing Technology. Recent Patents on Biotechnology, 2007. 1(2): p. 151-166.

7. Kong, S., J. Aucamp, and N.J. Titchener-Hooker, Studies on membrane sterile filtration of plasmid DNA using an automated multiwell technique. Journal of Membrane Science, 2010. 353(1-2): p. 144-150.

8. Levy, M.S., et al., Effect of shear on plasmid DNA in solution. Bioprocess and Biosystems Engineering, 1999. 20(1): p. 7-13.

9. Bakhshayeshi, M., et al., Use of confocal scanning laser microscopy to study virus retention during virus filtration. Journal of Membrane Science, 2011. 379(1-2): p. 260-267.

10. Ferrando, M., et al., An approach to membrane fouling characterization by confocal scanning laser microscopy. Journal of Membrane Science, 2005. 250(1-2): p. 283-293.

11. Zeman, L., Characterization of microfiltration membranes by image analysis of electron micrographs.: Part II. Functional and morphological parameters. Journal of Membrane Science, 1992. 71(3): p. 233-246.

12. Hermia, J., Constant pressure blocking filtration laws-application to power law non-Newtonian fluids. Chemical Engineering Research and Design, 1982. 60a: p. 183-187.

13. Bolton, G., D. LaCasse, and R. Kuriyel, Combined models of membrane fouling: Development and application to microfiltration and ultrafiltration of biological fluids. Journal of Membrane Science, 2006. 277(1-2): p. 75-84.

14. Ho, C.-C. and A.L. Zydney, A Combined Pore Blockage and Cake Filtration Model for Protein Fouling during Microfiltration. Journal of Colloid and Interface Science, 2000. 232(2): p. 389-399.

15. Zydney, A.L. and C.-C. Ho, Scale-up of microfiltration systems: fouling phenomena and Vmax analysis. Desalination, 2002. 146(1-3): p. 75-81.

16. Laska, M.E., et al., Robust scale-up of dead end filtration: Impact of filter fouling mechanisms and flow distribution. Biotechnology and Bioengineering, 2005. 92(3): p. 308-320.

17. Iritani, E., et al., Flux decline behavior in dead-end microfiltration of protein solutions. Journal of Membrane Science, 1995. 103(1-2): p. 181-191.

18. Bowen, W.R., J.I. Calvo, and A. Hernández, Steps of membrane blocking in flux decline during protein microfiltration. Journal of Membrane Science, 1995. 101(1-2): p. 153-165. 
19. Rajniak, P., et al., Sterilizing filtration--Principles and practice for successful scale-up to manufacturing. Journal of Membrane Science, 2008. 325(1): p. 223-237.

20. Haber, C., et al., Membrane chromatography of DNA: Conformation-induced capacity and selectivity. Biotechnology and Bioengineering, 2004. 88(1): p. 26-34.

21. Larson, J.W., et al., Single DNA molecule stretching in sudden mixed shear and elongational microflows. Lab on Chip, 2006. 6: p. 1187.

22. Wubbolts, M.G., O. Favre-Bulle, and B. Witholt, Biosynthesis of synthons in two-liquid-phase media. Biotechnology and Bioengineering, 1996. 52(2): p. 301-308.

23. Kim, M.-m. and A.L. Zydney, Particle-particle interactions during normal flow filtration: Model simulations. Chemical Engineering Science, 2005. 60(15): p. 4073-4082.

24. Tracey, E.M. and R.H. Davis, Protein Fouling of Track-Etched Polycarbonate Microfiltration Membranes. Journal of Colloid and Interface Science, 1994. 167(1): p. 104-116.

25. Bowen, W.R. and Q. Gan, Properties of microfiltration membranes: Flux loss during constant pressure permeation of bovine serum albumin. Biotechnology and Bioengineering, 1991. 38(7): p. 688-696.

26. Kelly, S.T., W. Senyo Opong, and A.L. Zydney, The influence of protein aggregates on the fouling of microfiltration membranes during stirred cell filtration. Journal of Membrane Science, 1993. 80(1): p. 175-187.

27. Hirasaki, T., et al., Permeation mechanism of DNA molecules in solution through cuprammonium regenerated cellulose hollow fiber (BMMtm). Journal of Membrane Science, 1995. 106(1-2): p. 123-129.

28. Watson, M.P., et al., Sterilizing filtration of plasmid DNA: Effects of plasmid concentration, molecular weight, and conformation. Biotechnology Progress, 2006. 22(2): p. 465-470.

29. Kong, S., N. Titchener-Hooker, and M.S. Levy, Plasmid DNA processing for gene therapy and vaccination: Studies on the membrane sterilisation filtration step. Journal of Membrane Science, 2006. 280(1-2): p. 824-831.

30. Morão, A.M., et al., Ultrafiltration of supercoiled plasmid DNA: Modeling and application. Journal of Membrane Science, 2011. 378(1-2): p. 280-289. 


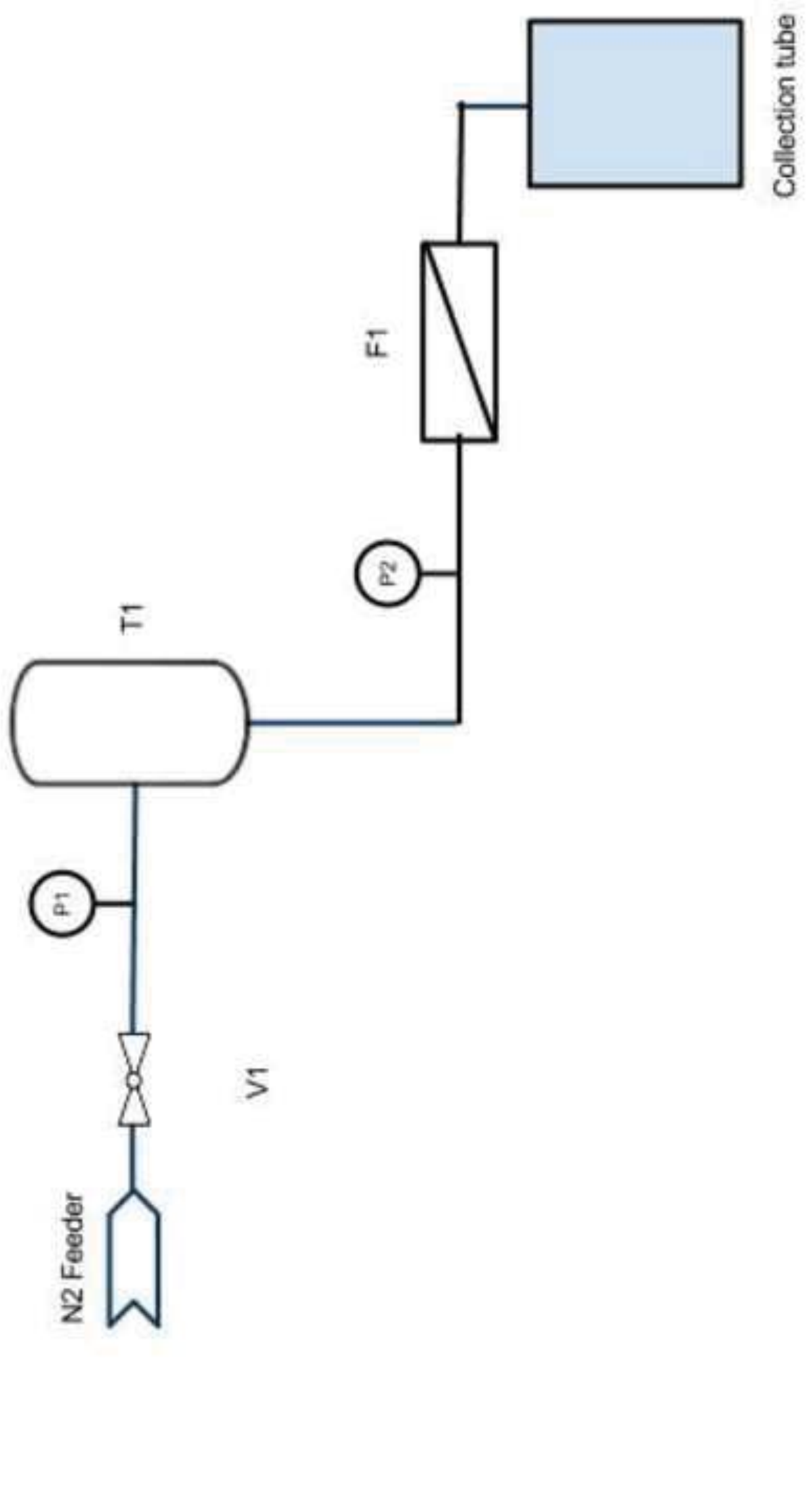



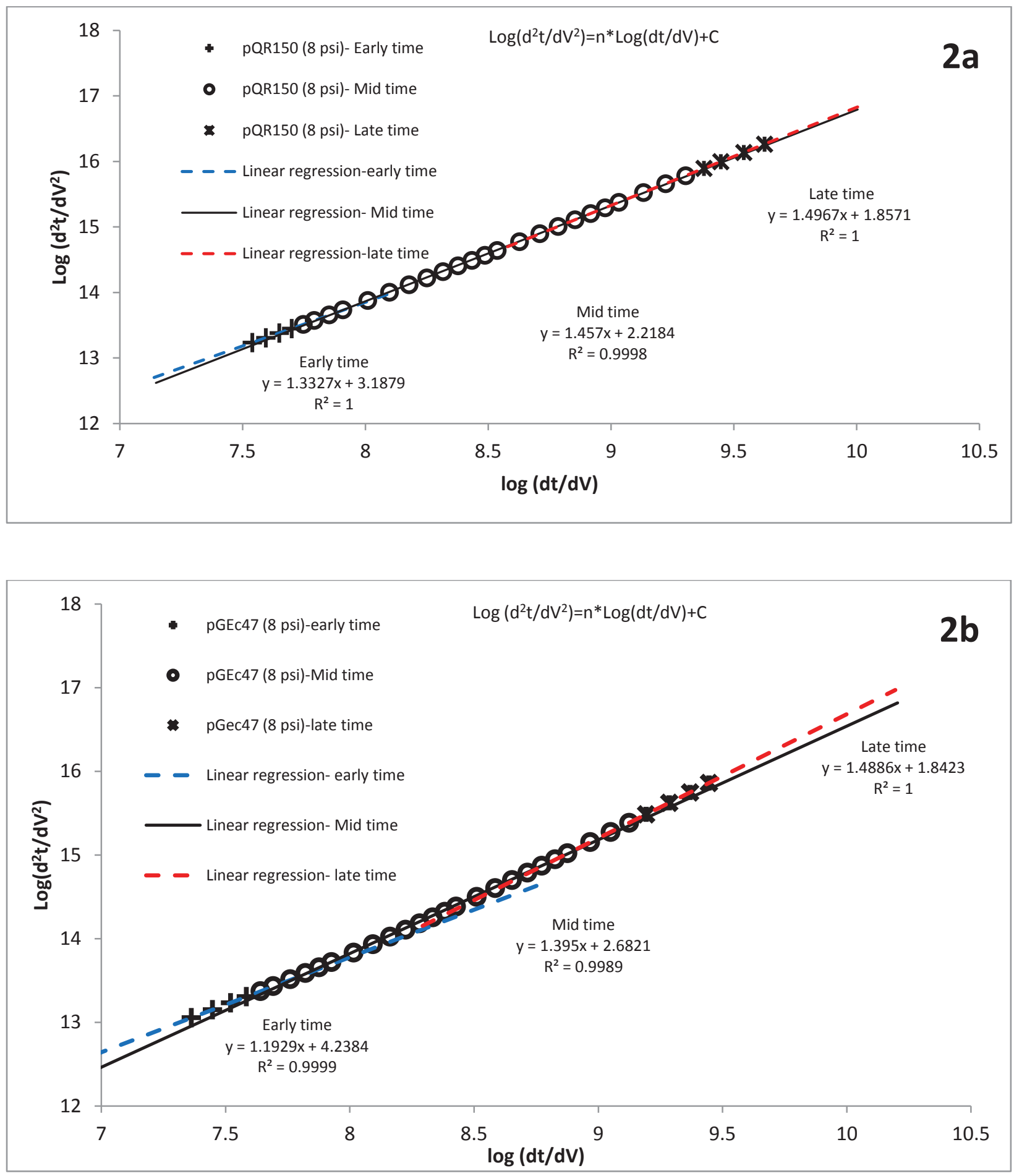

Figure 1- Flux decline analysis of pQR150 (20 kb) and pGEc47 (56 kb) filtrations at 8 psi transmembrane pressure. 


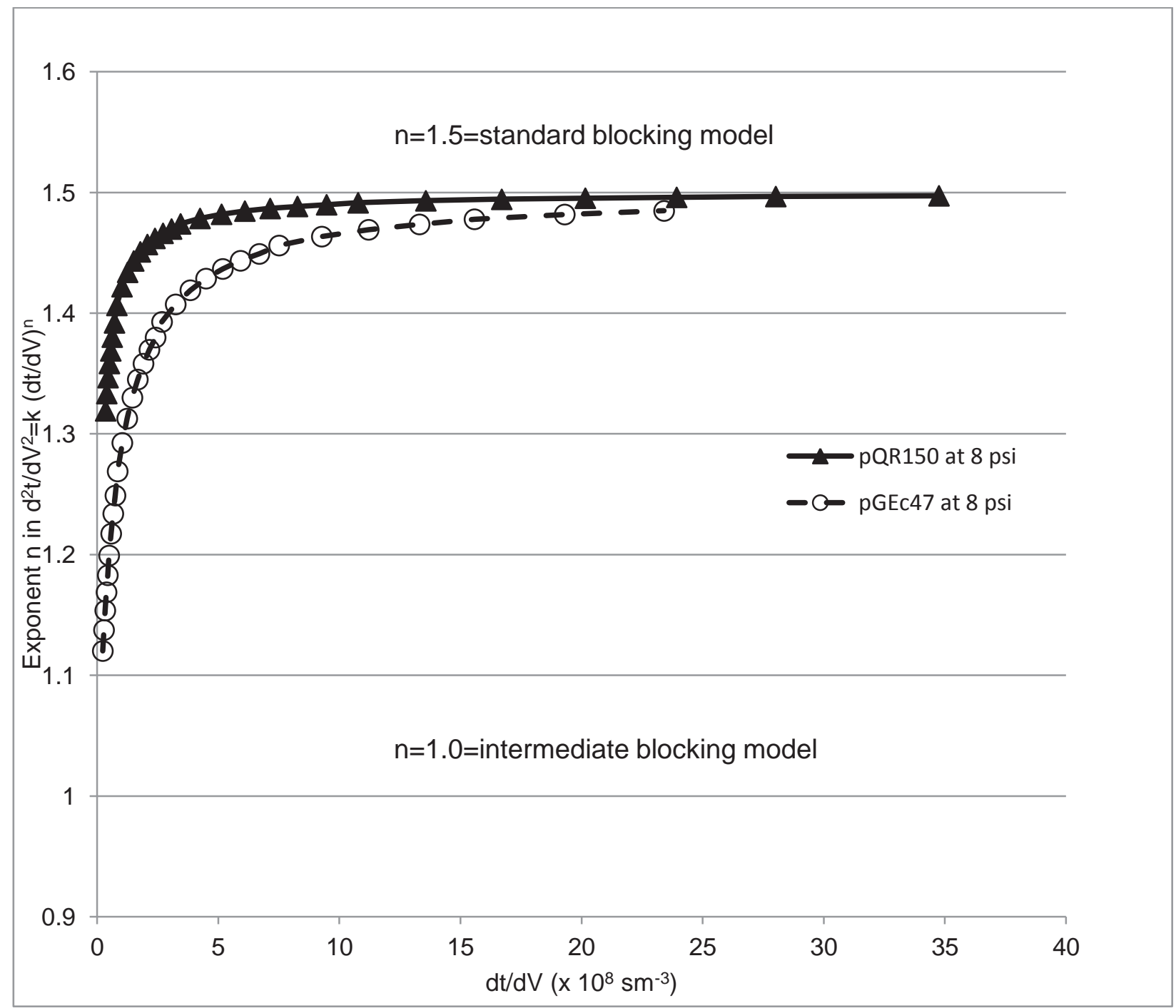

Figure 1 - The plot of exponent $n$ (Equation 1) vs. $d t / d V$ of the filtration of pQR150 (20 kb) and pGEc47 $(56 \mathrm{~kb})$ at 8 psi transmembrane pressure. 

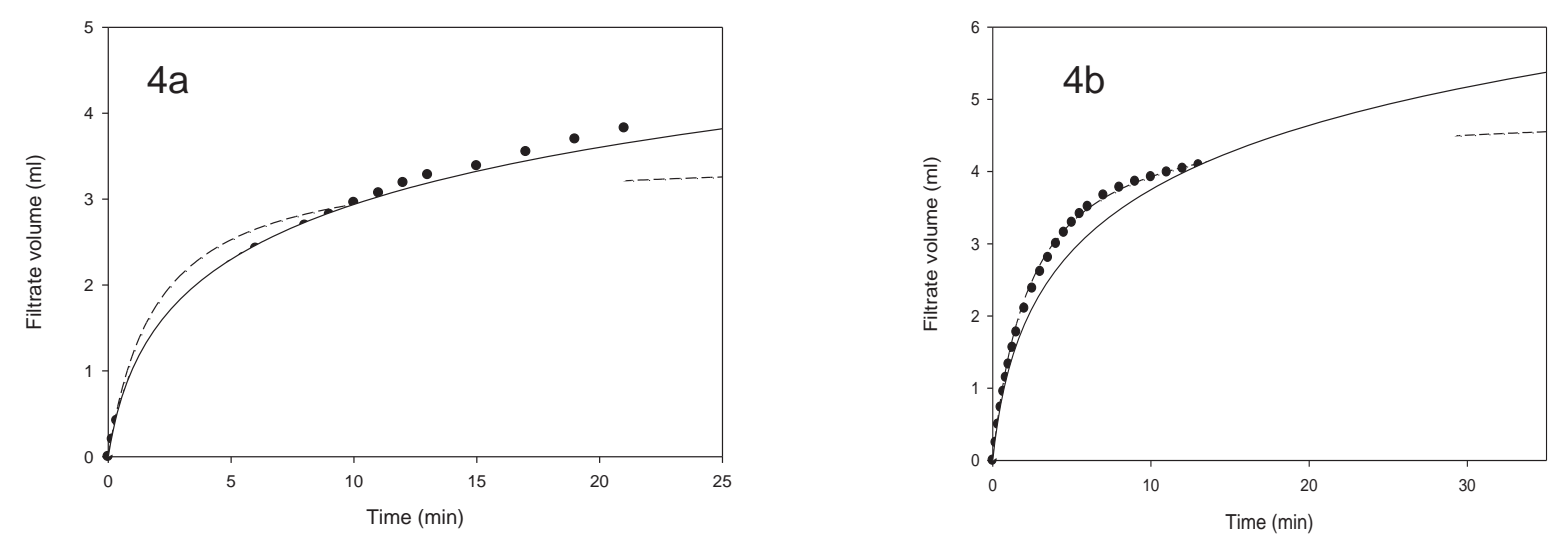

- Experimental data Intermediate model

- Experimental data Intermediate model
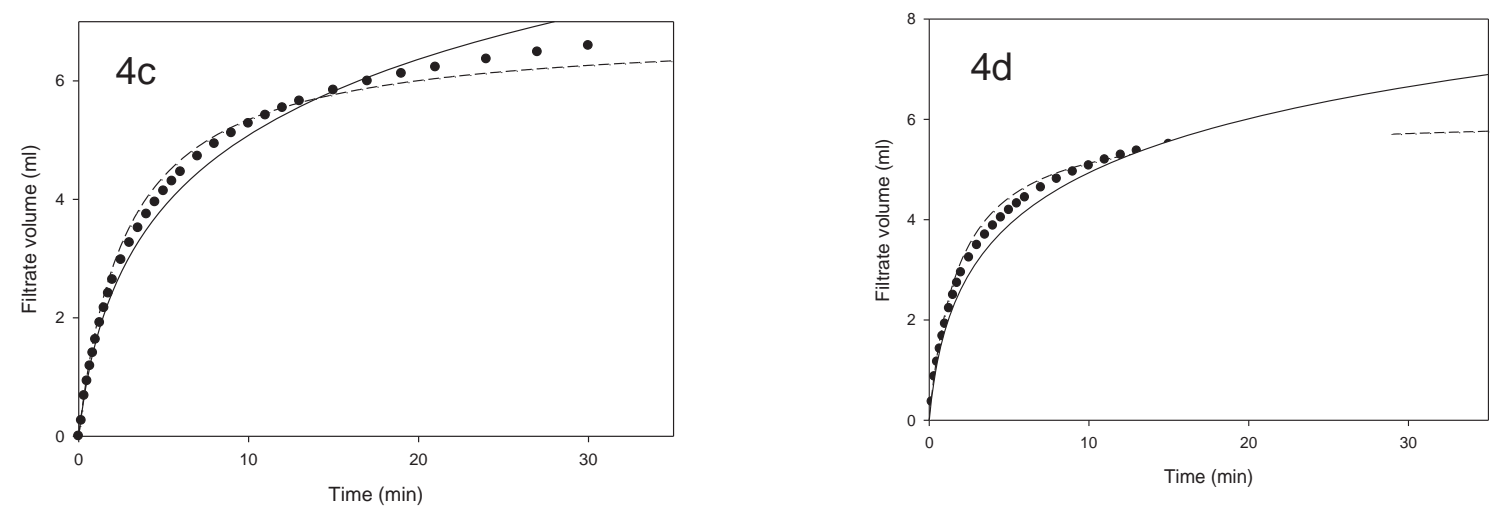

- Experimental data Intermediate model

- Experimental data
-_. Standard model Intermediate model

Figure 1 - Experimental data of filtrate volume vs. time fitted with the standard and intermediate blocking models. Solution containing $50 \mu \mathrm{g} / \mathrm{ml}$ of plasmid was filtered through $0.22 \mu \mathrm{m}$ PVDF membrane. Figure 4a represents pQR150 (20 kb) at 5 psi, 4b) pQR150 (20 $\mathrm{kb})$ at $8 \mathrm{psi}, 4 \mathrm{c})$ pGEc45 (56 kb) at $5 \mathrm{psi}$ and $4 \mathrm{~d})$ pGEc47 (56 kb) at 8 psi transmembrane pressure. 


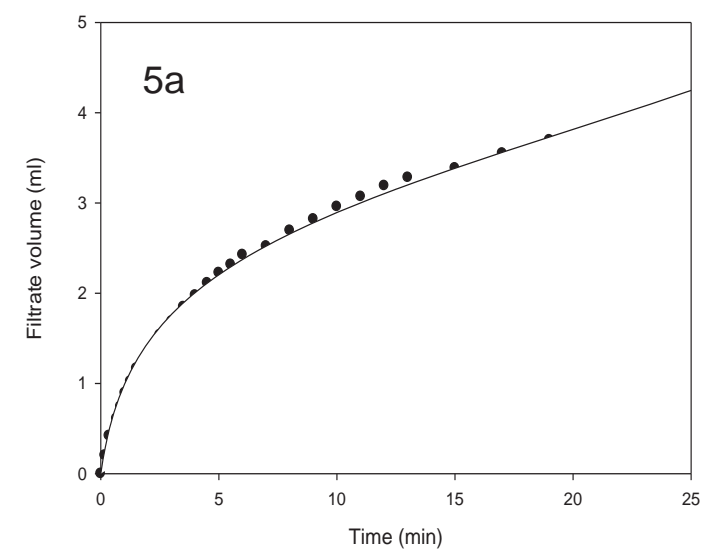

- Experimental data Intermediate-standard model

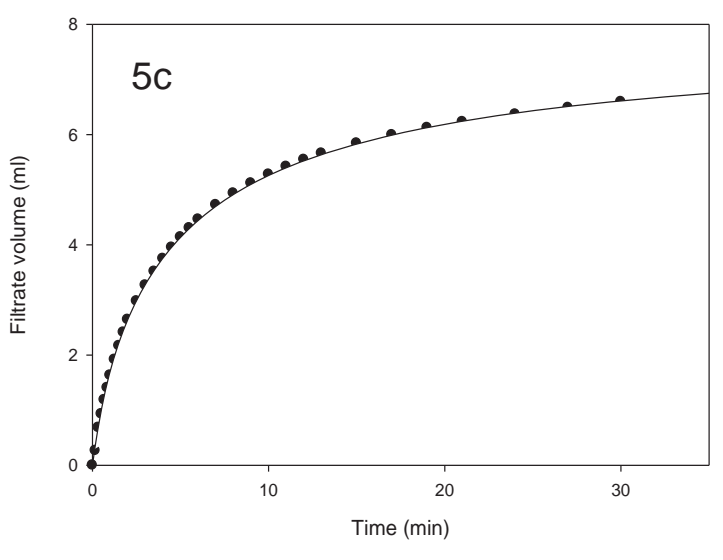

- Experimental data Intermediate-standard model

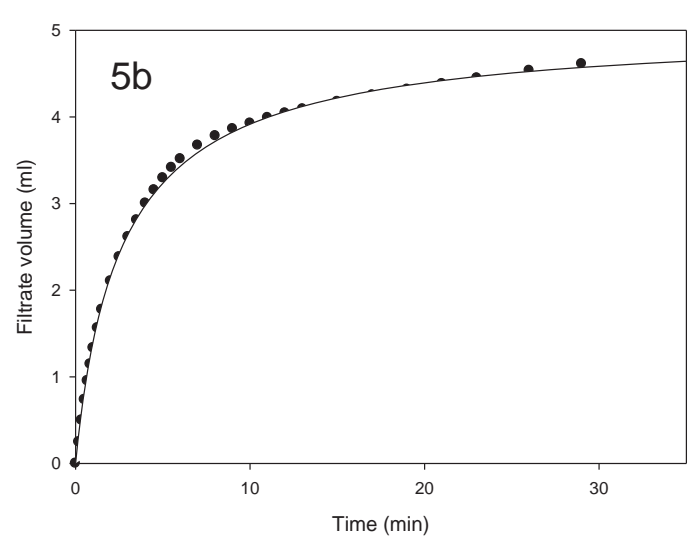

- Experimental data Intermediate-standard model

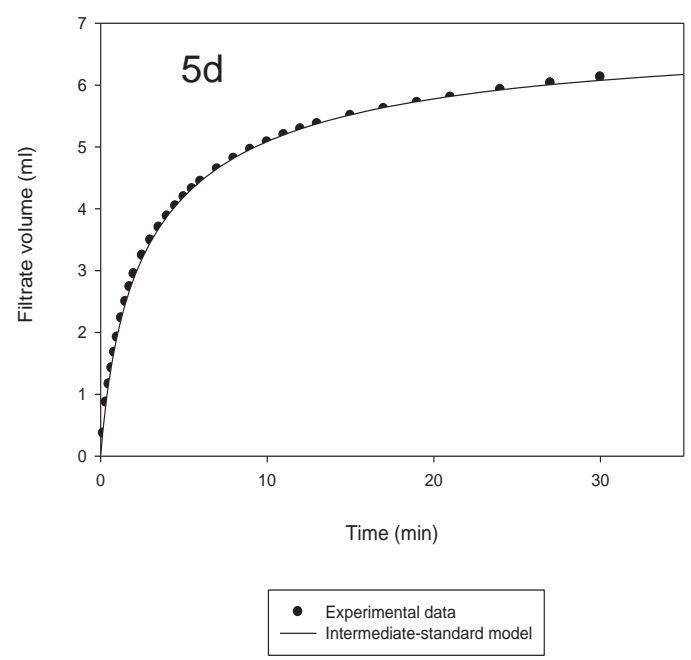

Figure 1- Experimental data of filtrate volume vs. time fitted with the intermediate-standard blocking model. Solution containing $50 \mu \mathrm{g} / \mathrm{ml}$ of plasmid was filtered through $0.22 \mu \mathrm{m}$ PVDF membrane. Figure 4a represents pQR150 (20 kb) at 5 psi, 4b) pQR150 (20 kb) at 8 psi, 4c) pGEc45 (56 kb) at 5 psi and 4d) pGEc47 (56 kb) at 8 psi transmembrane pressure. 

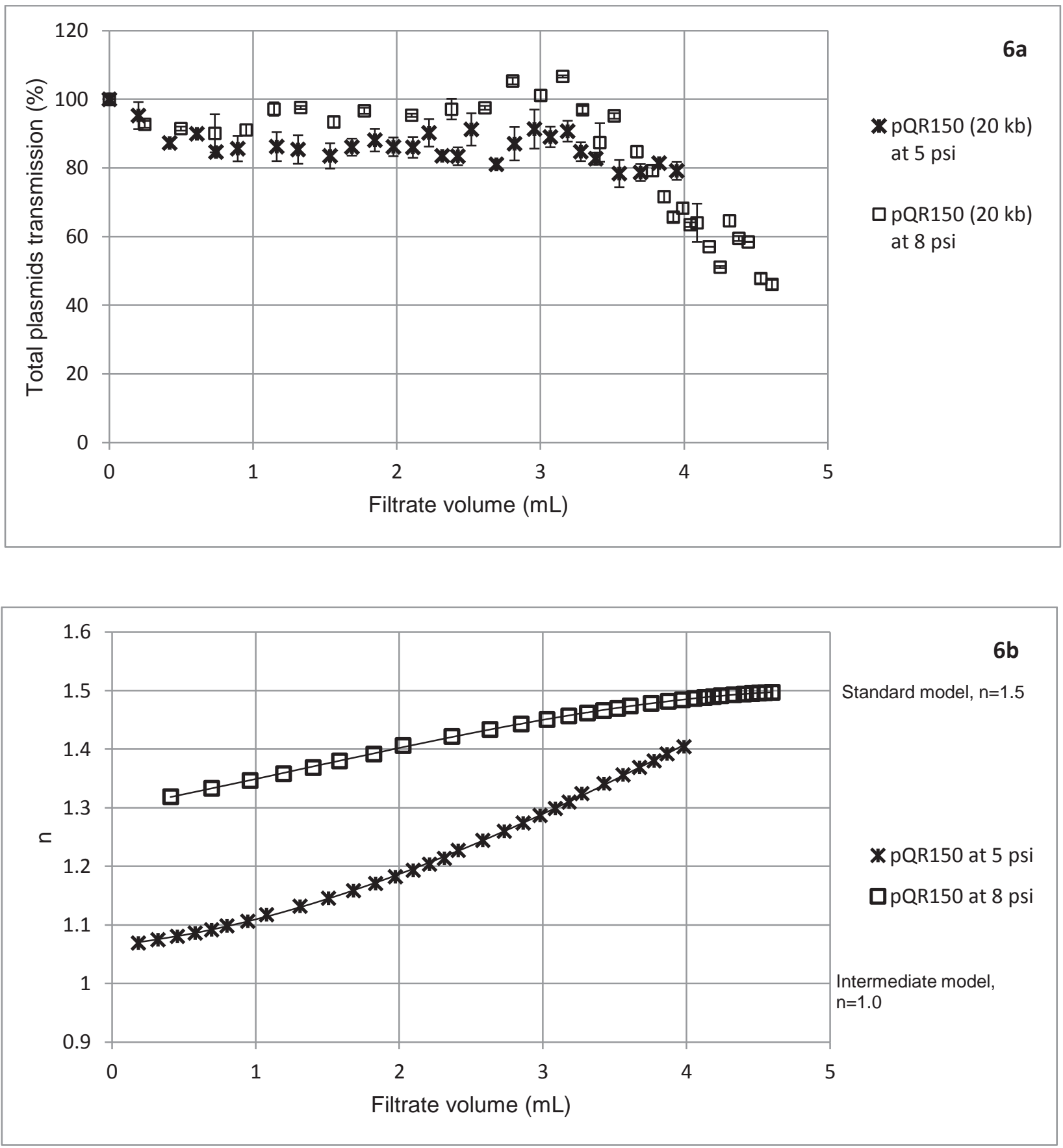

Figure 1- The transmission of pQR150 (20 kb) through $0.22 \mu \mathrm{m}$ PVDF membranes at 5 and $8 \mathrm{psi}$ constant pressure filtration. The plasmids were collected in batches and the total transmission was determined by the ratio of concentration of filtrate to the concentration of feed. Error bars in Fig 6a indicate the standard deviation. 

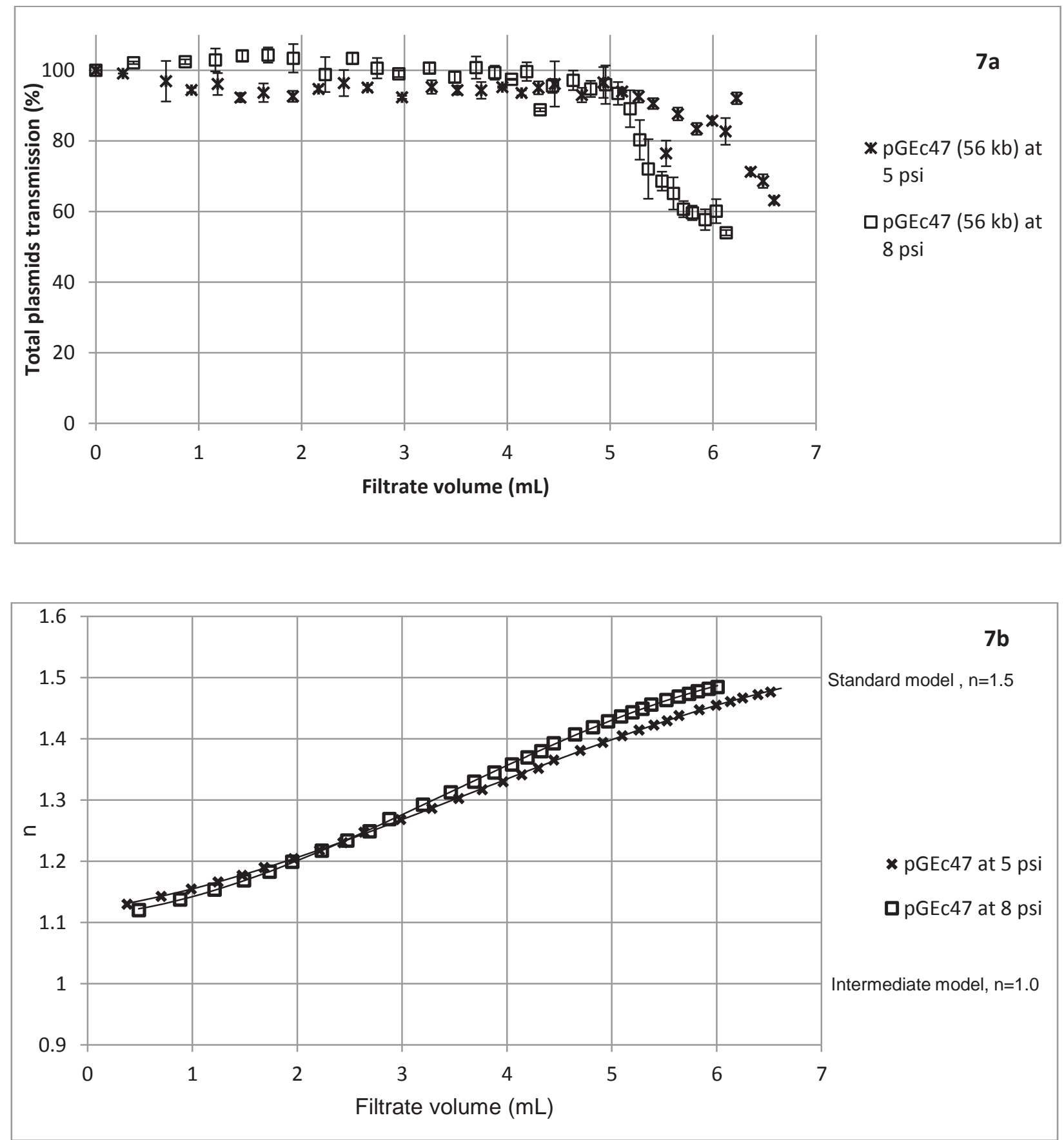

Figure 1- The transmission of pGEc47 (56 kb) through $0.22 \mu \mathrm{m}$ PVDF membranes at 5 and 8 psi constant pressure filtration. The plasmids were collected in batches and the total transmission was determined by the ratio of concentration of filtrate to the concentration of feed. Error bars in Fig 7a indicate the standard deviation. 
Standard blocking [16]

$$
V=\left(V_{0} t\right)\left(1+\frac{k_{s} V_{0}}{A_{0}} t\right)^{-1} \quad k_{s}\left(\mathrm{~m}^{-1}\right)
$$

Intermediate blocking [16]

$$
V=\frac{1}{k_{i}} \ln \left(1+k_{i} V_{0} t\right)
$$

$k_{i}\left(\mathrm{~m}^{-3}\right)$

Complete blocking [16]

$$
V=\frac{V_{0}}{k_{b}}\left[1-\exp \left(-k_{b} t\right)\right]
$$

Cake filtration [16]

$$
V=\frac{1}{V_{0} k_{c}}\left(\sqrt{1+\left(2 k_{c} V_{0}^{2} t\right)}-1\right)
$$

$$
k_{c}\left(\mathrm{~s} \cdot \mathrm{m}^{-6}\right)
$$

Intermediate-standard [13] $\quad V=\frac{A_{0}}{k_{i c}} \ln \left(1+\frac{2 k_{i c}\left(V_{0} / A_{0}\right) t}{2+k_{s}\left(V_{0} / A_{0}\right) t}\right) \quad k_{i c}\left(\mathrm{~m}^{-1}\right)$ and $k_{\mathrm{s}}\left(\mathrm{m}^{-1}\right)$

Complete-standard [13] $\quad V=\frac{V_{0}}{k_{b}}\left(1-\exp \left(\frac{-2 k_{b} t}{2+k_{s}\left(V_{0} / A_{0}\right) t}\right)\right) k_{b}\left(\mathrm{~s}^{-1}\right)$ and $k_{\mathrm{s}}\left(\mathrm{m}^{-1}\right)$

Table 1- Summary of classical and combined blocking models for constant transmembrane pressure filtration 


\begin{tabular}{llcc}
\hline Plasmid & Model & $\begin{array}{c}\text { Standard error of estimates } \\
\text { 5psi transmembrane } \\
\text { pressure }\end{array}$ & $\begin{array}{c}\text { Standard error of estimates } \\
\text { 8psi transmembrane } \\
\text { pressure }\end{array}$ \\
\hline pQR150 & Standard & 0.325 & 0.078 \\
& Intermediate & 0.120 & 0.272 \\
\hline pGEc47 & Standard & 0.191 & 0.342 \\
& Intermediate & 0.221 & 0.198 \\
\hline
\end{tabular}

Table 1 - Standard error of estimates of the filtration of pQR150 $(20 \mathrm{~kb})$ and pGEc47 $(56 \mathrm{~kb})$ at 5 and 8 psi. 


\begin{tabular}{llcc}
\hline Plasmid & Model & $\begin{array}{c}\text { Standard error of estimates } \\
5 \text { psi transmembrane } \\
\text { pressure }\end{array}$ & $\begin{array}{c}\text { Standard error of estimates } \\
8 \text { psi transmembrane } \\
\text { pressure }\end{array}$ \\
\hline pQR150 & $\begin{array}{l}\text { Intermediate- } \\
\text { standard }\end{array}$ & 0.077 & 0.061 \\
pGEc47 & $\begin{array}{l}\text { Intermediate- } \\
\text { standard }\end{array}$ & 0.035 & 0.165 \\
\hline
\end{tabular}

Table 1 - The model fit errors of the filtration of pQR150 and pGEc47 at 5 and 8 psi transmembrane pressures. 


\begin{tabular}{lcccc}
\hline \multirow{2}{*}{ Plasmid } & \multicolumn{2}{c}{$\begin{array}{c}\text { psi transmembrane } \\
\text { pressure }\end{array}$} & \multicolumn{2}{c}{$\begin{array}{c}\text { psi transmembrane } \\
\text { pressure }\end{array}$} \\
\cline { 2 - 5 } & $k_{i c}\left(\mathrm{~m}^{-1}\right)$ & $k_{\mathrm{s}}\left(\mathrm{m}^{-1}\right)$ & $k_{i c}\left(\mathrm{~m}^{-1}\right)$ & $k_{\mathrm{s}}\left(\mathrm{m}^{-1}\right)$ \\
\hline pQR150 & 62.14 & 4.10 & 30.51 & 16.75 \\
pGEc47 & 35.68 & 4.72 & 43.44 & 4.66 \\
\hline
\end{tabular}

Table 1- The fouling parameters of the filtration of pQR150 and pGEc47 at 5 and 8 psi transmembrane pressures 